Article

\title{
Stereocomplexation Reinforced High Strength Poly(L-lactide)/Nanohydroxyapatite Composites for Potential Bone Repair Applications
}

\author{
Naishun Guo, Mengen Zhao, Sijing Li, Jiahui Hao, Zhaoying Wu * and Chao Zhang *(D)
}

check for updates

Citation: Guo, N.; Zhao, M.; Li, S.;

Hao, J.; Wu, Z.; Zhang, C.

Stereocomplexation Reinforced High Strength Poly(L-lactide)/

Nanohydroxyapatite Composites for Potential Bone Repair Applications.

Polymers 2022, 14, 645. https://

doi.org/10.3390/polym14030645

Academic Editor: Haw-Ming

Huang

Received: 9 January 2022

Accepted: 5 February 2022

Published: 8 February 2022

Publisher's Note: MDPI stays neutral with regard to jurisdictional claims in published maps and institutional affiliations.

Copyright: (C) 2022 by the authors. Licensee MDPI, Basel, Switzerland. This article is an open access article distributed under the terms and conditions of the Creative Commons Attribution (CC BY) license (https:// creativecommons.org/licenses/by/ $4.0 /)$.

\author{
School of Biomedical Engineering, Shenzhen Campus of Sun Yat-sen University, Shenzhen 518107, China; \\ guonsh@mail2.sysu.edu.cn (N.G.); zhaomen@mail2.sysu.edu.cn (M.Z.); lisj8@mail2.sysu.edu.cn (S.L.); \\ haojh@mail2.sysu.edu.cn (J.H.) \\ * Correspondence: wuzhy37@mail.sysu.edu.cn (Z.W.); zhchao9@mail.sysu.edu.cn (C.Z.); \\ Tel.: +86-20-39332145 (Z.W. \& C.Z.)
}

\begin{abstract}
Composite materials composed of polylactide (PLA) and nano-hydroxyapatite (n-HA) have been recognized as excellent candidate material in bone repai The difference in hydrophilicity/hydrophobicity and poor interfacial compatibility between n-HA filler and PLA matrix leads to non-uniform dispersion of n-HA in PLA matrix and consequent poor reinforcement effect. In this study, an HA/PLA nanocomposite was designed based on the surface modification of n-HA with poly(D-lactide) (PDLA), which not only can improve the dispersion of n-HA in the poly(L-lactide) (PLLA) matrix but also could form a stereocomplex crystal with the matrix PLLA at the interface and ultimately lead to greatly enhanced mechanical performance The n-HA/PLA composites were characterized by means of scanning electron microscopy, Fourier transform infrared spectroscopy, $\mathrm{X}$-Ray diffraction, thermal gravity analysis, differential scanning calorimetry, and a mechanical test; in vitro cytotoxicity of the composite material as well as its efficacy in inducing osteogenic differentiation of rat bone marrow stromal cells (rMSCs) were also evaluated. Compared with those of neat PLLA, the tensile strength, Young's modulus, interfacial shear strength, elongation at break and crystallinity of the composites increased by $34 \%, 53 \%, 26 \%, 70 \%$, and $17 \%$, respectively. The adhesion and proliferation as well as the osteogenic differentiation of rMSCs on HA/PLA composites were clearly evidenced. Therefore, the HA/PLA composites have great potential for bone repai.
\end{abstract}

Keywords: polylactide; hydroxyapatite; nanocomposite; stereocomplex; mechanical property

\section{Introduction}

As one of the most popular biodegradable polymers, poly(lactic acid)/polylactide (PLA) has attracted tremendous attention as a biomaterial, owing to its excellent biocompatibility and biodegradability [1,2]; efforts have been devoted to its applications as a drug delivery matrix, tissue engineering scaffold, and, in addition, orthopedic implants [3,4]. In order to meet the clinical requirements of long-term orthopaedic implantation, the problems of inadequate mechanical properties and poor osseointegration of PLA need to be solved. Firstly, the brittleness of PLA may increase the risk of mechanical failure [5]. Second, the biological inertness of PLA usually results in low affinity to osteoblast [6]. In addition, the acidic degradation products after implantation could eventually lead to aseptic inflammation at the implantation site [7].

Bioactive inorganic fillers can be used to effectively improve the mechanical strength and the biological activity of PLA $[8,9]$. Commonly used inorganic fillers include hydroxyapatite (HA), $\beta$-tricalcium phosphate $(\beta-\mathrm{TCP})$, bioglass $(\mathrm{BG})$, and calcium carbonate, etc. [10-12]. The bioactivity of PLA composites with these inorganic fillers comes from the dissolution of calcium ion, phosphate ion, and, in addition, silicate ions; these ions can not only act as the calcium source in the mineralization but also promote the proliferation and 
osteogenic differentiation of osteoprogenitor cells or bone marrow stromal cells (rMSCs) through different signaling pathways [13-18]. Furthermore, the nano-sized inorganic fillers are conducive to the interaction between osteoblasts and biomaterial surface The addition of inorganic fillers into the PLA matrix may also produce a rough surface, which favors the adhesion and spreading of the osteoblast [19-21]. In addition, the bioactive inorganic fillers, such as HA [22] and BG [23], could induce the onset of crystallization and re-mineralization.

In the case of the composite materials of n-HA and PLA, due to the large difference in hydrophilicity/hydrophobicity between n-HA particles and PLA, prestine n-HA can hardly be dispersed uniformly in the PLA matrix, which makes it difficult to achieve nano-reinforcement $[24,25]$. In fact, the agglomeration of n-HA in the PLA matrix may pose a detrimental effect on the mechanical properties of the PLA/HA nanocomposite [26]. Classical strategies applied to solve the above problems usually involve the surface modification of n-HA using a silane coupling agent or hydrophobic/non-polar alkyl/polymeric chain Rocha et al. modified the surface of the HA with fatty acids (adipic, sebacic, lauric, and linoleic), which was then compounded with PLLA. It was found that the graft chain length and the presence of double $\mathrm{COOH}$ groups were more favorable to improve the interfacial interactions, and the tensile strength increased from 15 to $25 \mathrm{MPa}$ [27]. In addition, supramolecular interaction, hydrogen bonding, and stereocomplexation are also used to enhance the interaction between filler and PLA matrix, strengthen the interface integration, and improve the reinforcement effect $[28,29]$.

The intermolecular interaction between PLA chains has been utilized to improve the interfacial interaction between the n-HA filler and PLA matrix; generally, PLA oligomers are grafted onto n-HA to achieve better dispersion in the PLA matrix and improve the mechanical propertie It has been reported that stereocomplex could form between enantiomeric poly(L-lactide) (PLLA) and poly(D-lactide) (PDLA) in solution, oriented drawing, interface, hot drawing, and even during 3D printing [30-34]; the stereocomplex produces numerous dense, micron-sized crystals that act as cross-linking points between polymer chains and connect the high-density "tie chains" between crystals, thereby significantly improving the mechanical properties [35]. The tensile strength and Young's modulus of PDLA/PLLA blend films are at least 30\% higher than those of the corresponding pure PLLA films in almost any molecular weight rang The presence of stereocomplex crystals in the PLA matrix not only improves the mechanical properties but also enhances the crystallinity and thermal stability [36].

Grafting PDLA chains onto inorganic fillers may enhance the interfacial adhesion between the PLA matrix and inorganic phase [37]. PDLA-grafted magnesium oxide (MgO), titanium dioxide $\left(\mathrm{TiO}_{2}\right)$, ferroferric oxide $\left(\mathrm{Fe}_{3} \mathrm{O}_{4}\right)$, and clay have been explored to prepare composite materials with PLLA [38-41]. Kum et al., grafted PDLA oligomers onto the surface of $\mathrm{MgO}$ nanorods and then compounded them with PLLA. The tensile strength and modulus of the nanocomposite films increased by $20 \%$ due to the formation of the stereocomplex [38]. Huang et al. grafted PDLA and PLLA with different molar masses onto the HA surface and then compounded with the PLLA. The tensile strength increased from 62 to $72 \mathrm{MPa}$. The strengthening effect was stronger in the case of the PDLA-grafted HA instead of the PLLA with similar molar mas However, the low activity of the hydroxyl groups on the HA surface leads to a low grafting rate $(6.2 \%)$, which hinders the improvement of mechanical properties [42]. Therefore, improving the grafting rate of the PDLA on the HA surface is a promising strategy to obtain high strength PLLA/HA nanocomposite

In this study, an n-HA/PLA nanocomposite was designed based on the surface modification of n-HA with PDLA and its potential reinforcement with matrix PLLA through the stereocomplexation. First, the surface of n-HA was silanized using a silane-coupling agent; subsequently, the ROP of D-lactide initiated by the hydroxyl group on the surface of n-HA was performed to produce an n-HA with the covalently grafted PDLA on the surface (mHA) at a high grafting rati The $\mathrm{mHA}$ was then compounded with PLLA $\left(\mathrm{M}_{\mathrm{W}}=1350 \mathrm{~kg} / \mathrm{mol}\right)$ to fabricate mHA/PLA nanocomposites via solution casting. The mHA/PLA nanocomposites were comprehensively characterized in terms of fracture morphology, mechanical proper- 
ties, thermal properties, crystallinity, and crystallization kinetic The in vitro cytotoxicity and osteogenic capability of the mHA/PLA nanocomposites toward rat bone marrow stromal cells (rMSCs) were also evaluated.

\section{Materials and Methods}

\subsection{Materials}

D-Lactide (DLA, 99\%, Shenzhen Bright China Industrial C, Ltd., Shenzhen, China) was recrystallized from anhydrous ethyl acetate before us PLLA (weight average molar mass $\left(\mathrm{M}_{\mathrm{W}}\right)=1350 \mathrm{~kg} / \mathrm{mol}$, Dalian Meilun Biological Technology C, Ltd., Dalian, China), calcium nitrate tetrahydrate $\left(\mathrm{Ca}\left(\mathrm{NO}_{3}\right)_{2} \cdot 4 \mathrm{H}_{2} \mathrm{O}, 99 \%\right.$, Sigma-Aldrich, St. Louis, MI, USA) and diammonium phosphate $\left(\left(\mathrm{NH}_{4}\right)_{2} \mathrm{HPO}_{4}, 99 \%\right.$, Sigma-Aldrich, St. Louis, MI, USA) were used as received. Tin (II) 2-ethylhexanoate $\left(\mathrm{Sn}(\mathrm{Oct})_{2}\right.$, Sigma-Aldrich, St. Louis, MI, USA) was re-distilled under vacuum before us Other reagents were of analytical grade and used without purification. Acicular n-HA and clavate n-HA (Nanjing EPRI nano material C, Ltd., Nanjing, China) were dried at $100{ }^{\circ} \mathrm{C}$ overnight before use, and schistose n-HA was synthesized in the lab according to the literature report (See Appendix A).

Fetal bovine serum (FBS, Gibco Life Technologies, Grand Island, NE, USA), penicillinstreptomycin (Pen/Strep, Gibco Life Technologies, Grand Island, NE, USA), bovine serum albumin (BSA, Gibco Life Technologies, Grand Island, NE, USA), Dulbecco's modified Eagle medium (DMEM, Gibco Life Technologies, Grand Island, NE, USA), Alizarin red S (ARS, ScienCell, San Diego, CA, USA), Alkaline Phosphatase (ALP) assay kit (Beyotime, Shanghai, China), bicinchoninic acid (BCA) protein assay kit (Beyotime, Shanghai, China), paraformaldehyde (PFA, Servicebio, Wuhan, China), $10 \mathrm{mM} \beta$-glycerophosphate(SigmaAldrich, St. Louis, MI, USA), 100 nM dexamethasone (Sigma-Aldrich, St. Louis, MI, USA), Triton X-100 (Amresco, Washington, WA, USA), Osteocalcin monoclonal antibody (eBioscience, San Diego, CA, USA, 1:400 diluted in 1\% BSA before use), Goat Anti-Mouse IgG H\&L (Alexa Fluor ${ }^{\circledR}$ 488) (Invitrogen, Chicago, IL, USA, 1:500 diluted in 1\% BSA before use) and 4',6-diamidino-2-phenylindole (DAPI, Beyotime, Shanghai, China, 1:500 diluted in $1 \%$ BSA before use) were used as received.

Rat bone marrow stromal cells (rMSCs) were isolated from the femurs and tibias of 2-week-old male Sprague-Dawley rats (Laboratory Animal Centre of Sun Yat-sen University, Guangzhou, China) following the reported protocol [43], and cultured in growth medium (GM) containing DMEM supplemented with 10\% FBS and 1\% Pen/strep. Osteogenic medium (OM) was prepared by adding 10\% of FBS, 1\% of Pen/strep, $10 \mathrm{mM}$ of $\beta$-glycerophosphate, $50 \mu \mathrm{M}$ of vitamin $\mathrm{C}$ and $100 \mathrm{nM}$ of dexamethasone to the DMEM.

\subsection{Surface Modification of $n-H A$}

A total of $5.0 \mathrm{~g}$ of $\mathrm{n}-\mathrm{HA}$ was dispersed in a $30 \mathrm{~mL}$ of a mixture of ethanol and DI at $10^{\circ} \mathrm{A}$ hydrolysate comprising $30 \mathrm{~mL}$ ethanol and water mixed with $1.0 \mathrm{~g}$ of the silane-coupling agent (3-Aminopropyltriethoxysilane (APTEOS)) was added. The $\mathrm{pH}$ was adjusted to 9-10 by adding $10 \%$ sodium hydroxide solution. The reaction solution was heated to $70{ }^{\circ} \mathrm{C}$ and the temperature was maintained for $8 \mathrm{~h}$ at a constant stirring of $400 \mathrm{rpm}$. This was followed by centrifugation to separate the product, washing with hot DI water three times, and vacuum drying at $130{ }^{\circ} \mathrm{C}$ for $8 \mathrm{~h}$ to yield HA@APTEOS.

Subsequently, n-HA grafted with PDLA (mHA) was synthesized via the ROP of Dlactide from the surface of n-HA, during which the hydroxyl group on the n-HA surface acted as the initiato In detail, the anhydrous HA@APTEOS and D-lactide were transferred to a silanized glass ampoule at feed ratio of $1: 4$; to this mixture was added $\mathrm{Sn}(\mathrm{Oct})_{2}$ $(0.1 \mathrm{wt} \%)$ as a catalyst, and the ampoule was purged with $\mathrm{N}_{2}$ for three times and then sealed under vacuum ( $<20 \mathrm{~Pa})$. The reaction was performed at $140{ }^{\circ} \mathrm{C}$ for $48 \mathrm{~h}$ and cooled to room temperatur The crude product was extracted with dichloromethane five times and vacuum dried at $60{ }^{\circ} \mathrm{C}$ for $48 \mathrm{~h}$ to yield mHA. The mHA was made from n-HA with different morphology, namely acicular n-HA( $\left.\mathrm{mHA}_{1}\right)$, clavate $n-\mathrm{HA}\left(\mathrm{mHA}_{2}\right)$ and schistose n-HA $\left(\mathrm{mHA}_{3}\right)$. 


\subsection{Solution Casting of $m H A_{1-3} / P L A$ Nanocomposite Films}

The $\mathrm{mHA}_{1-3} /$ PLA nanocomposite films were fabricated via solution casting. The mHA was dispersed in dichloromethane under ultrasonication and stirred continuously for $24 \mathrm{~h}$ to ensure that the PDLA chains on the surface of n-HA were fully extended. PLLA $\left(\mathrm{M}_{\mathrm{W}}=1350 \mathrm{~kg} / \mathrm{mol}\right)$ was dissolved in dichloromethane at a constant stirring rate of $600 \mathrm{rpm}$ for at least $24 \mathrm{~h}$ to achieve a homogeneous solution. The two solutions were mixed at predetermined ratio, stirred continuously at $600 \mathrm{rpm}$ for $24 \mathrm{~h}$, poured into a glass dish and evaporated slowly for $72 \mathrm{~h}$, after which the film was vacuum dried to constant weight. The films prepared by this method were denoted as $\mathrm{mHA}_{1} / \mathrm{PLA}, \mathrm{mHA}_{2} / \mathrm{PLA}$, and $\mathrm{mHA}_{3} / \mathrm{PLA}$ nanocomposites with a weight percentage of the corresponding $\mathrm{mHA}$ of $1.0 \mathrm{wt} \%$. In addition, composites of PLLA and different pristine $\mathrm{HA}\left(1.0 \mathrm{wt} \%\right.$ of $\mathrm{HA}_{1}$, $\mathrm{HA}_{2}$ and $\mathrm{HA}_{3}$, respectively) were fabricated as the control following the same protocol, and were named $\mathrm{HA}_{1} / \mathrm{PLA}, \mathrm{HA}_{2} / \mathrm{PLA}$ and $\mathrm{HA}_{3} / \mathrm{PLA}$, respectively.

\subsection{Characterizations}

\subsubsection{Scanning Electron Microscopy (SEM)}

The morphologies of $\mathrm{HA}_{1-3}$ and the fractured surfaces of PLLA and the $\mathrm{mHA}_{1-3} / \mathrm{PLA}$ nanocomposites were observed under SEM (Hitachi, Regulus 8230, Hitachi, Japan) at an accelerating voltage of $10 \mathrm{kV}$.

\subsubsection{Fourier Transform Infrared Spectroscopy (FT-IR)}

FT-IR spectra of HA, HA@APTEOS and mHA $_{1-3}$ were recorded at wavenumbers ranging from 4000 to $400 \mathrm{~cm}^{-1}$ and at a resolution of $4 \mathrm{~cm}^{-1}$, using a TENSOR II spectrometer (Bruker, Vector-22, Karlsruhe, Germany) by the $\mathrm{KBr}$ method.

\subsubsection{X-ray Diffraction (XRD)}

The phase and structural properties of $\mathrm{HA}_{1-3}$, PLLA and the $\mathrm{mHA}_{1-3} /$ PLA nanocomposites were investigated via XRD (PANalytical, Empyrean, Almelo, The Netherland) in a $2 \theta$ angular range of $5-60^{\circ}$ at a scan rate of $0.01^{\circ}$.

\subsubsection{Thermogravimetric Analysis (TGA)}

The PDLA oligomers grafted onto the surface of HA were quantified on a SMP/PF7548/ MET TGA equipment (Mettler Toledo, Zurich, Switzerland) under $\mathrm{N}_{2}$ atmosphere $(40 \mathrm{~mL} / \mathrm{min})$, and the samples were heated from room temperature to $600{ }^{\circ} \mathrm{C}$ at a heating rate of $10{ }^{\circ} \mathrm{C} / \mathrm{min}$.

\subsubsection{Dynamic Light Scattering (DLS)}

The particle size and distribution of $\mathrm{HA}_{1-3}$ and $\mathrm{mHA}_{1-3}$ were obtained through dynamic light scattering (DLS) analysis on a Zetasizer Nano ZS90 (Malvern, Malvern, UK), using dichloromethane as the solvent.

\subsubsection{Polarized Optical Microscopy (POM)}

The crystallizing processes of the PLLA and $\mathrm{mHA}_{1-3} / \mathrm{PLA}$ nanocomposites were observed under a DM2500 polarized optical microscope (Leica, Weztlar, Germany) on a THM S600 hot stage (Linkam, Lincoln, UK). The samples were heated from $30{ }^{\circ} \mathrm{C}$ to $250{ }^{\circ} \mathrm{C}$ at a rate of $30^{\circ} \mathrm{C} / \mathrm{min}$ and maintained at $250{ }^{\circ} \mathrm{C}$ for $3 \mathrm{~min}$. Micrographs of the spherulites were taken after a predetermined time interval during the isothermal crystallization at $120^{\circ} \mathrm{C}$.

\subsubsection{Tensile Testing}

The tensile properties of the samples were measured according to ASTM D882-02 using an Instron 5566 Tensile Tester (Instron, Boston, MA, USA) at a speed of $4 \mathrm{~mm} / \mathrm{min}$. The films were cut into custom strip samples (width: $10 \mathrm{~mm}$, total length: $70 \mathrm{~mm}$ and thickness: $<1 \mathrm{~mm}$ ) and the thicknesses of the samples were measured using a screw micromete Five 
identical samples of each type were fabricated. The interfacial shear strength formula applied was:

$$
\tau_{i}=\frac{P_{i}}{2 A}
$$

where $P_{i}$ is the maximum stress below a $5 \%$ strain $(\mathrm{N})$ and $A$ is the cross sectional area $\left(\mathrm{mm}^{2}\right)$.

\subsubsection{Differential Scanning Calorimetry (DSC)}

The thermal behavior and crystallinity of the samples was determined via DSC (Netzsch, DSC-204, Bavaria, Germany). Each sample ( $5 \mathrm{mg})$ was first heated from $30{ }^{\circ} \mathrm{C}$ to $240^{\circ}$ The temperature was maintained at $240^{\circ} \mathrm{C}$ for $5 \mathrm{~min}$ to eliminate the thermal history. Then, the samples were cooled to $30{ }^{\circ} \mathrm{C}$ at $10^{\circ} \mathrm{C} / \mathrm{min}$ and re-heated to $200{ }^{\circ} \mathrm{C}$ at $10{ }^{\circ} \mathrm{C} / \mathrm{min}$.

Non-isothermal crystallization test: First, the temperature was raised from room temperature to $240{ }^{\circ} \mathrm{C}$ at a heating rate of $20^{\circ} \mathrm{C} / \mathrm{min}$. The temperature was maintained for 3 min to eliminate the heating history. Then, the samples were cooled to room temperature at a cooling rate of $10^{\circ} \mathrm{C} / \mathrm{min}$. Finally, the temperatures of different samples were increased to $240{ }^{\circ} \mathrm{C}$ at heating rates of $1.25,2.50,5.00,7.50$ and $10.00^{\circ} \mathrm{C} / \mathrm{min}$, respectively.

The glass transition temperature $\left(T_{g}\right)$, cold crystallization temperature $\left(T_{c c}\right)$, melting temperature $\left(T_{m}\right)$, cold crystallization enthalpy $\left(\Delta H_{c \mathcal{c}}\right)$ and melting enthalpy $\left(\Delta H_{m}\right)$ were determined from the second heating scan. The crystallinity $\left(X_{c}\right)$ of neat PLLA, and the $\mathrm{mHA}_{1}$ /PLA, $\mathrm{mHA}_{2}$ /PLA and $\mathrm{mHA}_{3}$ / PLA nanocomposites were calculated using:

$$
X_{C}(\%)=\frac{\Delta H_{m}+\Delta H_{c c}}{\Delta H_{m}^{0} \times\left(1-\frac{w t . \% \text { filler }}{100}\right) \times 100}
$$

$\Delta H_{m}^{0}=93.0 \mathrm{~J} / \mathrm{g}$ is the melting enthalpy of a $100 \%$ pure crystalline sample of PLLA. $w t . \%$ filler $=5 \%$ is the weight percentage of $\mathrm{mHA}_{1-3}$.

The relative crystallinity $X(T)$ of the polymer was calculated using:

$$
X(T)=\frac{X_{c}\left(T_{O}\right)}{X_{c}\left(T_{\infty}\right)}=\frac{\int_{0}^{t} \frac{d H_{c}(t)}{d t} d t}{\int_{0}^{\infty} \frac{d H_{c}(t)}{d t} d t}
$$

where $T$ is the crystallization temperature at time $t, T_{O}$ is the temperature at the start of crystallization, $T_{\infty}$ is the temperature at the end of crystallization and $d H_{c}$ is the crystallization enthalpy released in the infinitely small $d T$ temperature rang

Crystallization temperature $(T)$ can be converted to crystallization time through the equation:

$$
t=\frac{|T o-T|}{\varnothing}
$$

where $\varnothing$ is heating rate, ${ }^{\circ} \mathrm{C} / \mathrm{min}$.

The non-isothermal crystallization kinetics of polymers were analyzed using the Avrami equation:

$$
\lg [-\ln (1-X(T))]=\lg Z_{t}-n \lg t
$$

where $n$ is the Avrami index and $Z_{t}$ is the crystallization rate $\left({ }^{\circ} \mathrm{C} / \mathrm{min}\right)$. For non-isothermal crystallization and to obtain the crystallization rate constant at a normalized heating rate, $A$. Jeziorny proposed the correction of $Z_{t}$ to $Z_{c}$ using the formula:

$$
\lg Z_{c}=\frac{\lg Z_{t}}{\varnothing}
$$

\subsubsection{Cell Seeding}

The PLA nancomposite films were cut into $10 \times 10 \mathrm{~mm}^{2}$ pieces and sterilized under UV irradiation overnight in a biosafety hood, and transferred to non-stick 24-well plat 
rMSCs suspension in $150 \mu \mathrm{L}$ of GM were added on the films at a seeding density of $2 \times 10^{4}$ cells/well, and incubated for four hours to allow cell attachment, then each well was filled with $500 \mu \mathrm{L}$ of GM. $24 \mathrm{~h}$ later, these films were transferred to $500 \mu \mathrm{L}$ of GM or $\mathrm{OM}$ at $37^{\circ} \mathrm{C}, 5 \% \mathrm{CO}_{2}$, and the medium was changed every $48 \mathrm{~h}$. The first time of changing the medium was defined as day 0 .

\subsubsection{Hemolytic Property of HA}

The hemolytic activity of $\mathrm{HA}, \mathrm{mHA}_{1}, \mathrm{mHA}_{2}$ and $\mathrm{mHA}_{3}$ was evaluated. In detail, rat erythrocytes were isolated from the rat blood, followed by centrifugation at $1000 \mathrm{rpm}$ for $10 \mathrm{~min}$ and treated with phosphate buffer (PBS; $\mathrm{pH}=7.4$ ) [44]. The HA/mHA dispersed in PBS was $0.0125,0.025,0.05$ and $0.1 \mathrm{~g} / \mathrm{mL}$ suspension was incubated at $37^{\circ} \mathrm{C}$ for three hours, and then centrifuged at $1000 \mathrm{r} / \mathrm{min}$ for $10 \mathrm{~min}$. The absorbance at $540 \mathrm{~nm}$ was measured on a Synergy-4 microplate reader (BioTek, Winooski, VT, USA). DI water was used as a positive control.

\subsubsection{Cytotoxicity of the $\mathrm{HA} / \mathrm{mHA}$}

The rMSCs suspension in $100 \mu \mathrm{L}$ of GM were seeded in 96-well plate at the density of $2 \times 10^{4}$ cells/well, and incubated for $24 \mathrm{~h}$; then, the medium was aspirated, and the wells were replenished with HA/mHA suspension in DMEM at varied concentrations $(0.0125$, $0.025,0.05$ and $0.1 \mathrm{~g} / \mathrm{mL}$ ) for $24 \mathrm{~h}$. Subsequently, the HA/mHA suspension was replaced by $100 \mu \mathrm{L}$ of GM and $10 \mu \mathrm{L}$ of CCK- 8 solution and incubated at $37^{\circ} \mathrm{C}$ for two hours, and the absorbance of the upper medium at $450 \mathrm{~nm}$ was measured on a Synergy-4 microplate reader (BioTek, Winooski, VT, USA).

\subsubsection{Cell Proliferation on mHA/PLA Composites}

Cells were seeded on PLA nancomposite films, as described abov At a predetermined time point (one, four and 7 days), the culture medium was aspirated, and the $\mathrm{mHA}_{1} / \mathrm{PLA}$ composite films were transferred to another 24-well plate to avoid the error from the cells growing on the bottom of the well; $500 \mu \mathrm{L}$ of GM and $50 \mu \mathrm{L}$ of CCK-8 solution were added to each well and incubated at $37^{\circ} \mathrm{C}$ for two hour Then, $100 \mu \mathrm{L}$ of the upper medium was transferred to a 96-well microplate and subjected to a measurement of the absorbance at $450 \mathrm{~nm}$ on a Synergy-4 microplate reader (BioTek, Winooski, VT, USA).

\subsubsection{Alizarin Red S (ARS) Staining and Quantification}

Calcium deposition (mineralization) on the surface of the PLA nancomposite films was assayed by ARS staining. After 7, 14 and 21 days of culture, the cells were fixed with $4 \%$ PFA at $37^{\circ} \mathrm{C}$ for $30 \mathrm{~min}$, then stained with $500 \mu \mathrm{L}$ of alizarin red solution $(2 \mathrm{w} / \mathrm{v} \%)$ for $30 \mathrm{~min}$. The staining solution was aspirated and washed with PBS until no nonspecific staining could be visually observed under the light microscop For a quantitative analysis, $500 \mu \mathrm{L}$ of cetylpyridinium chloride solution $(100 \mathrm{mM})$ in PBS was added to each well to dissolve the calcium deposition; then, $100 \mu \mathrm{L}$ of the supernatant was transferred to a 96-well plate and measured at $570 \mathrm{~nm}$ on a Synergy-4 microplate reader (BioTek, Winooski, VT, USA).

\subsubsection{ALP Activity Measurement}

The ALP activity of the cells on the PLA nanocomposite films was evaluated according to the previously reported method [45] on 3, 7 and 14 days of culture; and the ALP activity was also quantified using an ALP quantification kit according to the manufacturer's instruction.

\subsubsection{Osteocalcin (OCN) Immunofluorescence Staining}

After being cultured in osteogenic medium for 14 days, the cells on the surface of the nanocomposite were fixed with $4 \%$ PFA solution for $30 \mathrm{~min}$. Then, the samples were treated with $0.1 \%$ Triton X-100 for 5 min and blocked with 1\% BSA for $30 \mathrm{~min}$. Afterward, 
it was incubated with osteocalcin monoclonal antibody overnight at $4{ }^{\circ} \mathrm{C}$ and with Goat Anti-Mouse IgG H\&L (Alexa Fluor ${ }^{\circledR} 488$ ) for two hour Finally, the nuclei were stained with DAPI and observed under an OLYMPUS IX71 fluorescence microscope (Olympus, Hitachi, Japan).

\subsubsection{Confocal Laser Scanning Microscopy (CLSM)}

The morphologies of rMSCs cells cultured on PLA and $\mathrm{mHA}_{1} / \mathrm{PLA}$ films were observed under CLSM one day after inoculation. Before observation, the samples were washed with PBS and fixed with 4\% PFA at room temperature for $30 \mathrm{~min}$. After fixation, the cells were infiltrated by $0.1 \%$ Triton X-100 for 10 min and blocked with $1 \%$ BSA for 30 min; then, each sample was stained with Phalloidin-FITC for the F-actin filaments for $60 \mathrm{~min}$ and DAPI for the nucleus for $10 \mathrm{~min}$ in the dark. The samples were sealed on microscope slides and observed under a FV3000 CLSM (Olympus, Hitachi, Japan).

\subsubsection{Statistical Analysis}

All experiments were performed with at least three independent samples, and data were expressed as mean \pm standard deviation. Statistical comparisons were achieved using a one-way analysis of variance (ANOVA) or Student's $t$-test. $p<0.05$ was considered to be statistically significant. For all quantitative data, ${ }^{*}$ refers to $p<0.05,{ }^{* *}$ refers to $p<0.01$ and *** refers to $p<0.001$.

\section{Results and Discussion}

As observed under SEM (Figure A1), the acicular n-HA exhibited a length of approximately $450 \mathrm{~nm}$ and a length-to-diameter ratio greater than 10:1; the clavate n-HA was found to have an average length of $200 \mathrm{~nm}$ and an average diameter of $35 \mathrm{~nm}$; the schistose n-HA had an irregular quadrilateral shape with a width of approximately 50-100 nm and a length of approximately 150-200 nm with multilayer superposition.

The physicochemical properties of $\mathrm{mHA}_{1-3}$ were characterized by XRD, FTIR, TGA and DLS (Figure 1). It was found that diffraction peaks of $\mathrm{HA}_{1-3}$, corresponding to phase pure HA at the prominent planes (002), (211), (112), (310) and (202), etc., were obtained and matched with the JCPDS file n09-432 (Figure 1a). In the FTIR spectra (Figure 1b), the infrared spectrum of HA@APTEOS shows the characteristic peak of Si-O-Si at $1150 \mathrm{~cm}^{-1}$, indicating the successful grafting of the silane-coupling agent. The additional peak in the spectra of $\mathrm{mHA}_{1}, \mathrm{mHA}_{2}$ and $\mathrm{mHA}_{3}$ at $1750 \mathrm{~cm}^{-1}$ corresponds to the carbonyl group $(\mathrm{C}=\mathrm{O})$ and the $2900-3000 \mathrm{~cm}^{-1}$ corresponds to the alkyl groups $\left(\mathrm{CH}_{3}\right.$ - and $\left.-\mathrm{CH}_{2}-\right)$ of PDLA, indicating the successful grafting of D-lactid The TGA (Figure 1c) curves demonstrated that the decomposition of PDLA occurred at approximately $250{ }^{\circ} \mathrm{C}$, and HA was stable upon heating in $\mathrm{N}_{2}$. During the whole heating process, the mass loss of HA@APTEOS is $7.2 \%$. Therefore, the grafting amount of PDLA onto $\mathrm{HA}_{1-3}$ was able to be calculated from those weight losses of $\mathrm{mHA}_{1-3}$ in subtracting the weight loss of HA@APTEOS, which were found to be $24.8 \mathrm{wt} \%, 22.3 \mathrm{wt} \%$ and $21.9 \mathrm{wt} \%$, respectively, for $\mathrm{mHA}_{1}, \mathrm{mHA}_{2}$ and $\mathrm{mHA}_{3}$.

The average particle sizes of $\mathrm{HA}_{1}, \mathrm{HA}_{2}$ and $\mathrm{HA}_{3}$, as determined by the DLS method, were $400 \mathrm{~nm}, 350 \mathrm{~nm}$ and $800 \mathrm{~nm}$, respectively. In contrast, the average particle sizes of the $\mathrm{mHA}_{1}, \mathrm{mHA}_{2}$ and $\mathrm{mHA}_{3}$ samples were $240 \mathrm{~nm}, 160 \mathrm{~nm}$ and $700 \mathrm{~nm}$, respectively, displaying a smaller particle size and narrower particle size distribution than those of the $\mathrm{HA}_{1-3}$ (Figure 1d-f). This indicates that the surface-grafted PDLA prevented HA from aggregating in chloroform, thereby improving its dispersibility. 

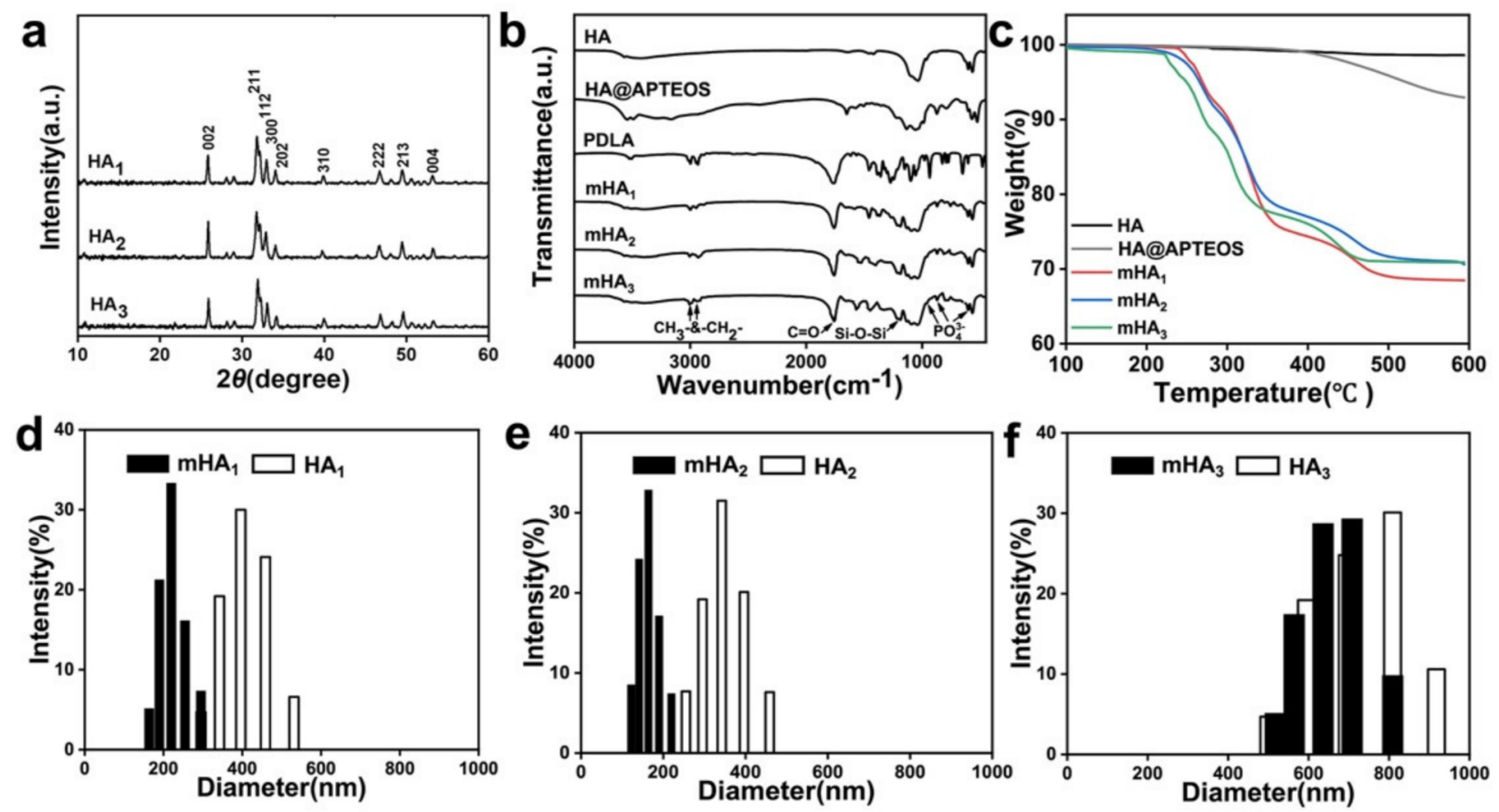

Figure 1. The basic physicochemical characterizations: (a) XRD pattern; (b) FTIR spectrum; and (c) TGA curv Particle size distributions of $\mathrm{HA}_{1-3}$ and $\mathrm{mHA}_{1-3}$ : (d) $\mathrm{HA}_{1}$ and $\mathrm{mHA}_{1} ;(\mathbf{e}) \mathrm{HA}_{2}$ and $\mathrm{mHA}_{2} ;$ (f) $\mathrm{HA}_{3}$ and $\mathrm{mHA}_{3}$.

The suspensions were allowed to stand for $12 \mathrm{~h}$ after sonication; it was found that the $\mathrm{HA}_{1-3}$ suspensions displayed poor stability in chloroform, and the $\mathrm{HA}_{1-3}$ particles slowly settled at the bottom of the ampoules (Figure 2a), with no significant precipitate observed in the $\mathrm{mHA}_{1-3}$ samples (Figure $2 \mathrm{~b}$ ). It was hypothesized that the PDLA chains on the surface of $\mathrm{mHA}_{1-3}$ swell and extend in chloroform, thereby preventing $\mathrm{mHA}_{1-3}$ from re-aggregating in the solvated stat Upon the mixing of $\mathrm{mHA}_{1-3}$ suspensions with PLLA solution, interactions between the PDLA chains on the $\mathrm{mHA}_{1-3}$ surface and the swollen PLLA chains may occur, significantly improving the stability of the suspensions and inhibited the precipitation of $\mathrm{mHA}_{1-3}$ in the mixture solution. This is critical for the fabrication of homogeneous $\mathrm{mHA}_{1-3} / \mathrm{PLA}$ nanocomposite films via the solution-casting technique, after which the $\mathrm{mHA}_{1-3}$ may be more evenly distributed in the PLLA matrix.

The mechanical performance of the $\mathrm{mHA}_{1-3} / \mathrm{PLA}$ nanocomposites was evaluated in terms of tensile strength, elongation-at-break, Young's modulus and interfacial shear strength, respectively (Figure 3). It was found that tensile strength of neat PLLA was approximately $67 \mathrm{MPa}$. After $1 \%$ of $\mathrm{HA}_{1}$ was added, the tensile strength increased slightly by approximately $2 \mathrm{MPa}$. This may be due to the significant agglomeration of $\mathrm{HA}_{1}$ in the matrix. However, the tensile strength increased from 67 to $79 \mathrm{MPa}$ with $1 \%$ of $\mathrm{mHA}_{1}$. The tensile strength gradually increased upon the content of $\mathrm{mHA}_{1}$, and a maximum tensile strength of $91 \mathrm{MPa}$ was achieved with $5 \%$ of mHA; as the content of $\mathrm{mHA}_{1}$ further increased to $10 \%$, the tensile strength decreased because the high content of $\mathrm{mHA}_{1}$ in the PLLA matrix may possibly affect the distribution of filler and develop defects, resulting in performance degradation. The elongation-at-break and tensile strength displayed similar trends, that is, when the content of $\mathrm{mHA}_{1}$ was $5 \%$, the elongation-at-break peaked at $11.6 \%$, which was higher than of the neat PLLA with a value of $6.5 \%$ (Figure $3 a$ ). At the content of $\mathrm{mHA}_{1}$ lower than $5 \%$, the Young's modulus and the interfacial shear strength of $\mathrm{mHA}_{1}$ $(5 \%) /$ PLA nanocomposite increased by $57 \%$ and $26 \%$, respectively (Figure $3 b$ ). According to the shear yield crazing theory $[46,47]$, when $\mathrm{mHA}_{1}$ was homogeneously dispersed in the PLA matrix, the stress concentration induced significant crazing, which absorbed a large 
amount of energy on impact. Moreover, the excellent interfacial interaction between $\mathrm{mHA}_{1}$ and PLLA can help control the propagation of crazing and prevent destructive cracking.
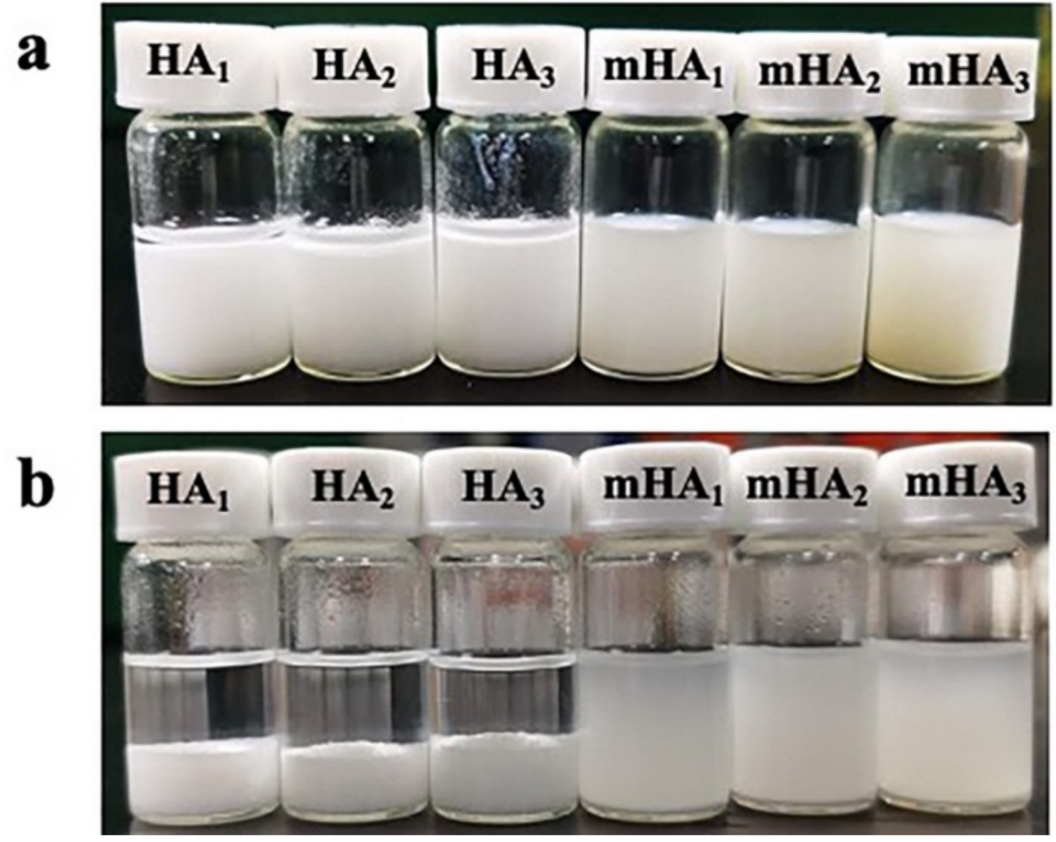

Figure 2. Stability of $\mathrm{HA}_{1-3}$ and $\mathrm{mHA}_{1-3}$ in chloroform. (a) Digital photos after $0 \mathrm{~h}$ and (b) after $12 \mathrm{~h}$.

In the $\mathrm{mHA}_{2} / \mathrm{PLA}$ nanocomposites, when increasing the content of $\mathrm{mHA}_{2}$ to $3 \%$, the tensile strength increased from 67 to $90 \mathrm{MPa}$; further increasing the content of $\mathrm{mHA}_{2}$ to $5 \%$ did not result in significant improvement of the tensile strength or elongation-at-break. The maximum Young's modulus, elongation-at-break and interfacial shear strength increased by $55 \%, 64 \%$ and $10 \%$, respectively, as compared with those of the neat PLLA (Figure 3c,d).

The $\mathrm{mHA}_{3} /$ PLA nanocomposite displayed a different reinforcing performance (Figure $3 e, f$ ). It was found that at the content of $\mathrm{mHA}_{3}$ of 3\%, this tensile strength was 31\% higher than that of PLA, which was also the highest value in the studied rang The Young's modulus, interfacial shear strength, and elongation-at-break increased by $50 \%, 21 \%$ and $60 \%$, respectively.

The improvement in mechanical properties at the interface between $\mathrm{mHA}_{1-3}$ and PLLA matrix may be attributed to the promotion of stress transfer by the uniformly dispersed high-modulus $\mathrm{mHA}_{1-3}$, which results in bifurcation and the deflection of micro-cracks, consequently facilitating energy dissipation. More importantly, due to the presence of intermolecular stereocomplexation, $\mathrm{mHA}_{1-3}$ can play a bridging role to prevent the propagation of micro-cracks at the interface. The $\mathrm{mHA}_{1-3}$ samples displayed different degrees of enhancement, which may be related to their degree of dispersion and siz

The fractured surfaces of $\mathrm{mHA}_{1-3} /$ PLA nanocomposites were observed under SEM (Figure 4). It was found that the neat PLLA displayed a typical single-phase morphology with a smooth surface, indicating a brittle fracture (Figure $4 a, a^{\prime}$ ). In the $\mathrm{mHA}_{1-3} /$ PLA nanocomposites, the rough surface with ductile dimples and tear edges was observed. This indicates that the addition of $\mathrm{mHA}_{1-3}$ caused the fractures of PLLA to change from brittle to ductil No noticeabe difference in the fractured surfaces of the $\mathrm{mHA}_{1} / \mathrm{PLA}, \mathrm{mHA}_{2} / \mathrm{PLA}$ and $\mathrm{mHA}_{3} /$ PLA nanocomposites was observed, although all of them were coarser than that of the neat PLLA. 

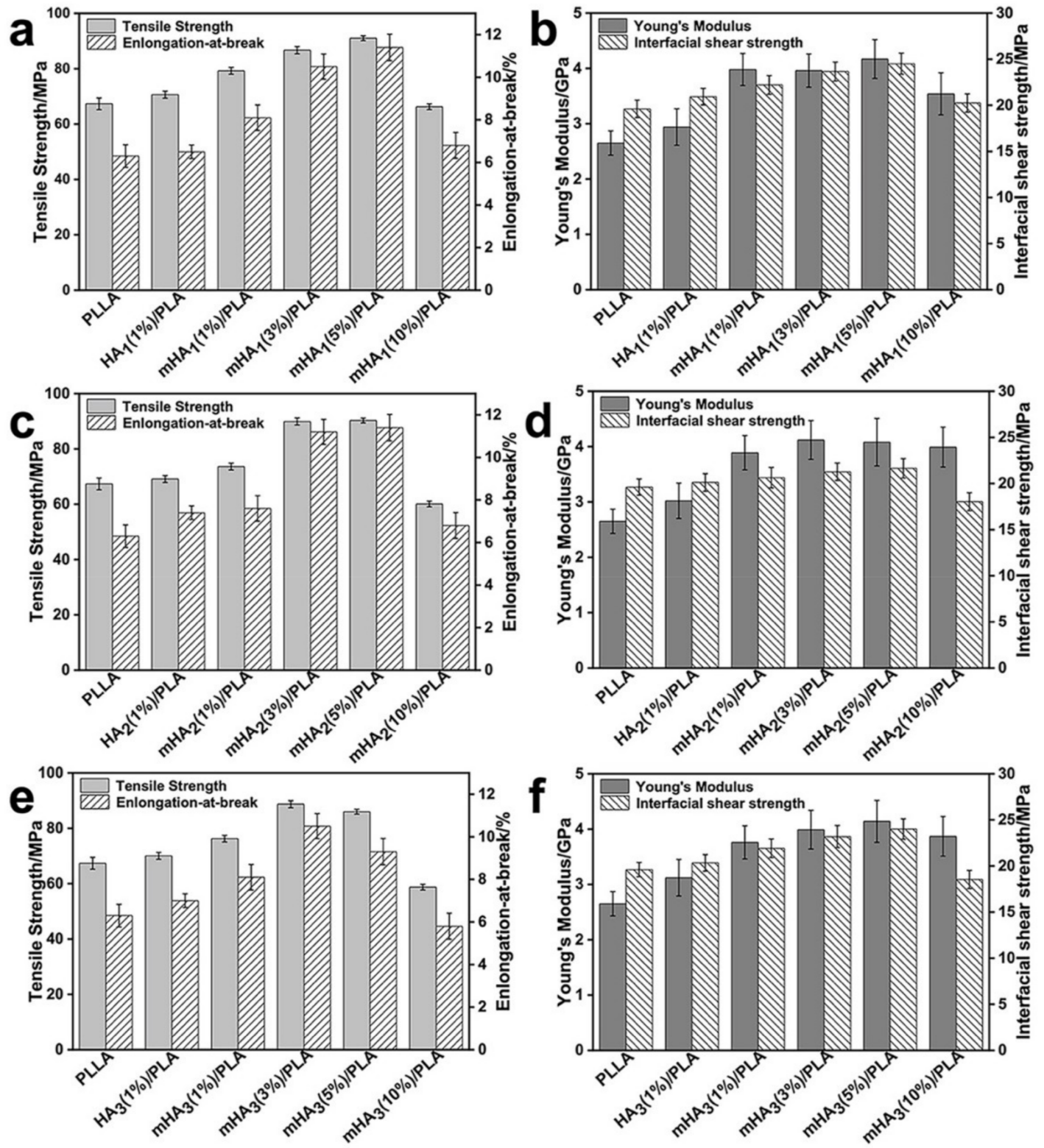

Figure 3. Mechanical properties of the $\mathrm{mHA}_{1-3} / \mathrm{PLA}$ composites: (c,d), $\mathrm{mHA}_{2} / \mathrm{PLA} ;(\mathbf{e}, \mathbf{f}), \mathrm{mHA}_{3} / \mathrm{PLA}$.

$(\mathbf{a}, \mathbf{b}), \quad \mathrm{mHA}_{1} / \mathrm{PLA}$;

The influence of $\mathrm{mHA}_{1}, \mathrm{mHA}_{2}$ and $\mathrm{mHA}_{3}$ on the crystallization behavior of the PLA matrix was studied (Figure 5). In the neat PLLA, a few spherulites appeared after 2 min and the number of spherulites increased slightly in the following 2 min (Figure 5a,a'). In contrast, numerous spherulites formed in the $\mathrm{mHA}_{1-3} / \mathrm{PLA}$ nanocomposites after 2 min and the spherulites covered almost the entire field of view after $2 \mathrm{~min}$. After the same time interval, the spherulites in the nanocomposites were more numerous and smalle Compared with $\mathrm{mHA}_{3} / \mathrm{PLA}$, more spherulites appeared in the $\mathrm{mHA}_{1} / \mathrm{PLA}$ and $\mathrm{mHA}_{2} / \mathrm{PLA}$ nanocomposites after $2 \mathrm{~min}$, with little difference in between them (Figure $5 \mathrm{~b}-\mathrm{d}$ ). At $4 \mathrm{~min}$, the spherulites of all the composites filled the entire field of view (Figure $5 b^{\prime}-d^{\prime}$ ). The improved crystallization of the PLLA matrix due to the addition of mHA $_{1-3}$ could be mainly attributed to the synergistic effect of $\mathrm{mHA}_{1-3}$ as the nucleating agent and stereocomplex crystals are nucleating site This synergistic effect promoted a higher nucleation density and a smaller spherulite size in the composites, which increased the crystallization rate [48]. 


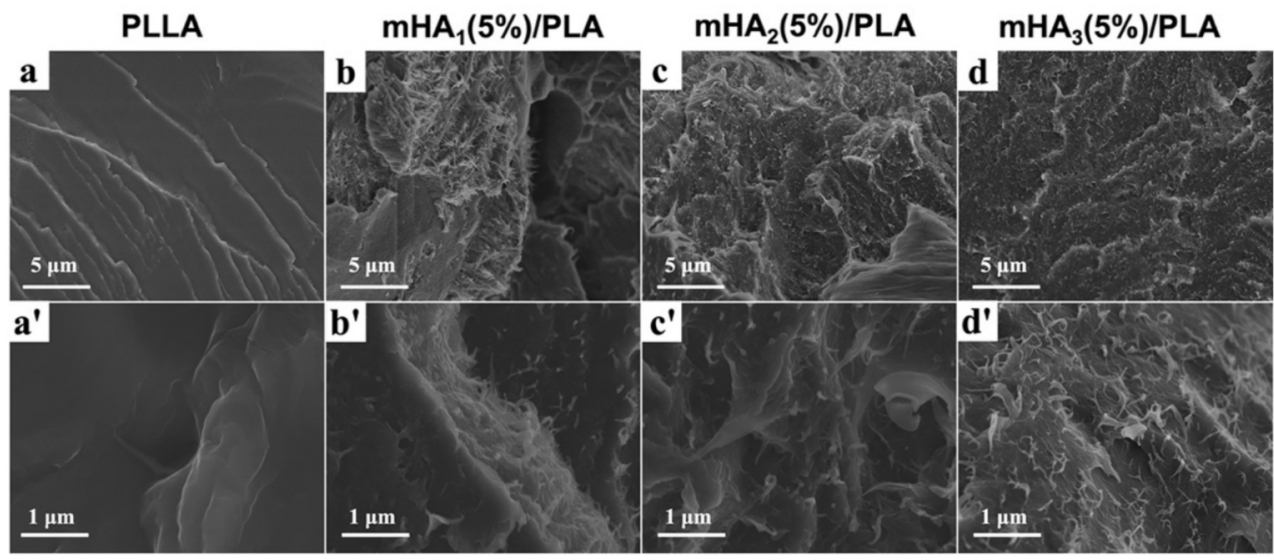

Figure 4. Fractured surfaces of $\mathrm{mHA}_{1-3} / \mathrm{PLA}$ nanocomposites: $\left(\mathbf{a}, \mathbf{a}^{\prime}\right), \operatorname{PLLA} ;\left(\mathbf{b}, \mathbf{b}^{\prime}\right), \mathrm{mHA}_{1} / \mathrm{PLA}$; $\left(\mathbf{c}, \mathbf{c}^{\prime}\right), \mathrm{mHA}_{2} / \mathrm{PLA} ;\left(\mathbf{d}, \mathbf{d}^{\prime}\right), \mathrm{mHA}_{3} /$ PLA.

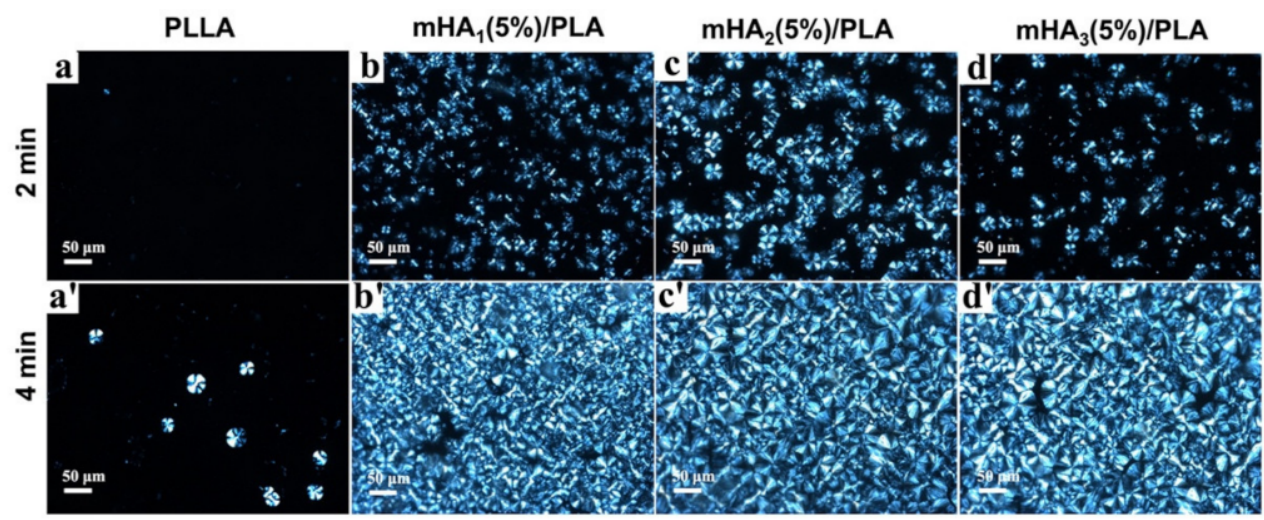

Figure 5. Polarized micrographs of $\mathrm{mHA}_{1-3} /$ PLA nanocomposites: (a/a') PLLA; (b/b') $\mathrm{mHA}_{1} /$ PLA; $\left(\mathbf{c} / \mathbf{c}^{\prime}\right) \mathrm{mHA}_{2} / \mathrm{PLA} ;\left(\mathbf{d} / \mathbf{d}^{\prime}\right) \mathrm{mHA}_{3} /$ PLA.

The crystallization behavior was further studied using DSC (Figure 6 and Table 1). In the first cooling curves, the intensity of the cooling crystallization peaks of the three nanocomposites was significantly higher than that of the neat PLLA (Figure 6a). In the second heating curves, the cold crystallization peaks of the $\mathrm{mHA}_{1-3} / \mathrm{PLA}$ nanocomposites shifted to lower temperatures, indicating that $\mathrm{mHA}_{1-3}$ as a nucleating agent promoted the crystallization of the nanocomposit Comparing the curves of the $\mathrm{mHA}_{1} / \mathrm{PLA}, \mathrm{mHA}_{2} / \mathrm{PLA}$ and $\mathrm{mHA}_{3} / \mathrm{PLA}$ nanocomposites, it is clear that the cold crystallization peak of $\mathrm{mHA}_{1} / \mathrm{PLA}$ was sharper than that of $\mathrm{mHA}_{2} / \mathrm{PLA}$ and $\mathrm{mHA}_{3} / \mathrm{PLA}$, indicating that $\mathrm{mHA}_{1}$ was more conducive to the crystallization of PLA (Figure $6 \mathrm{~b}$ ).

Table 1. Thermal properties and crystallinities of PLLA and the $\mathrm{HA}_{1-3} / \mathrm{PLA}$ nanocomposite.

\begin{tabular}{|c|c|c|c|c|c|c|}
\hline Samples & $\operatorname{Tg}\left({ }^{\circ} \mathrm{C}\right)$ & $\operatorname{Tcc}\left({ }^{\circ} \mathrm{C}\right)$ & $\operatorname{Tm}\left({ }^{\circ} \mathrm{C}\right)$ & $\Delta H m(\mathrm{~J} / \mathrm{g})$ & $\Delta H c c(\mathrm{~J} / \mathrm{g})$ & $X c(\%)$ \\
\hline Neat PLLA & 58.3 & 122.8 & 178.4 & 37.6 & -21.1 & 17.8 \\
\hline $\mathrm{mHA}_{1} / \mathrm{PLA}$ & 63.0 & 108.7 & 179.6 & 44.5 & -13.0 & 34.3 \\
\hline $\mathrm{mHA}_{2} / \mathrm{PLA}$ & 61.8 & 105.4 & 179.3 & 45.3 & -12.6 & 35.6 \\
\hline $\mathrm{mHA}_{3} / \mathrm{PLA}$ & 62.6 & 108.2 & 180.1 & 42.4 & -11.4 & 33.7 \\
\hline
\end{tabular}

$\mathrm{Tg}=$ glass transition temperature; $T c c=$ cold crystallization temperature; $T m=$ melting temperature $\Delta H m=$ melting enthalpy; $\Delta H c c=$ cold crystallization enthalpy; $X c=$ degree of crystallinity. 

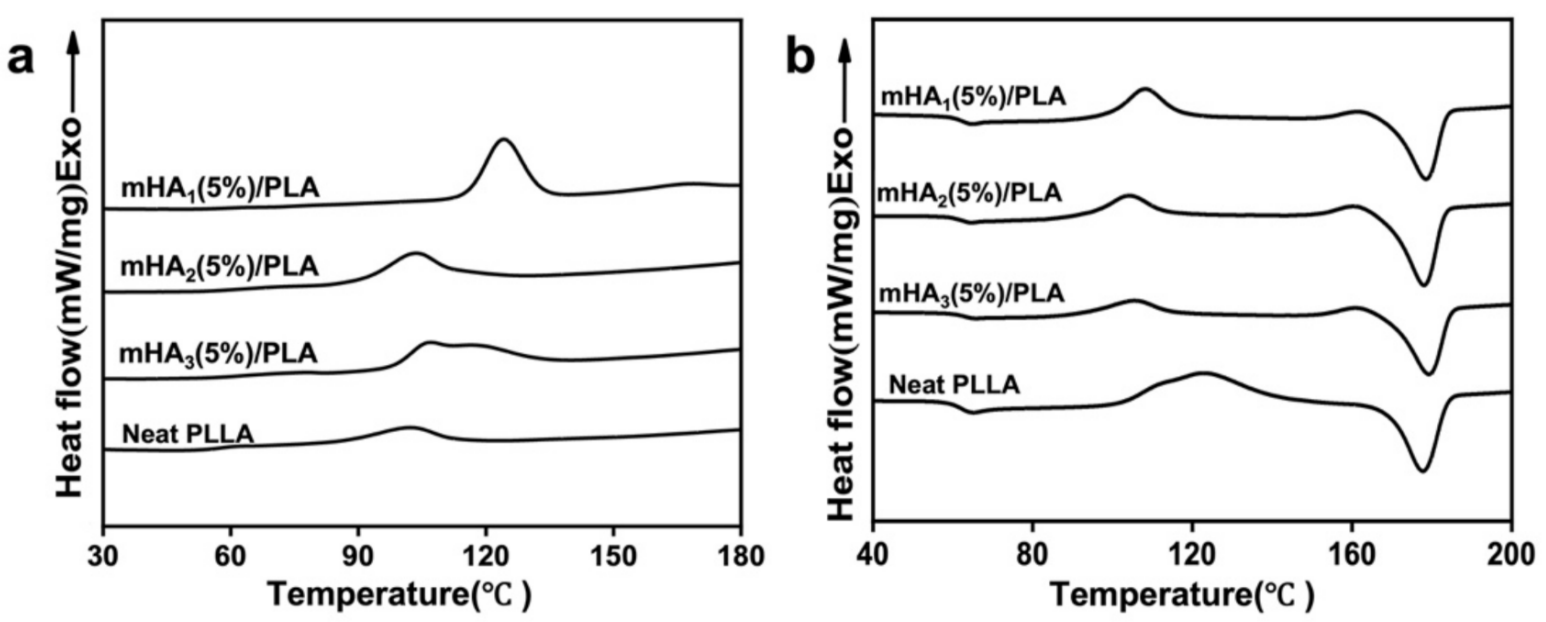

Figure 6. DSC curves of $\mathrm{mHA}_{1-3}$ /PLA nanocomposites: (a) first cooling scan; (b) second heating scan.

Compared with neat PLLA, the crystallinities of $\mathrm{mHA}_{1} / \mathrm{PLA}, \mathrm{mHA}_{2} / \mathrm{PLA}$ and $\mathrm{mHA}_{3} /$ PLA increased by $92.7 \%, 100.0 \%$ and $89.3 \%$, respectively. The ability of $\mathrm{mHA}_{1-3}$ to promote crystallization could be attributed to the synergistic effect of $\mathrm{mHA}_{1-3}$ as a nucleating agent and the stereocomplex crystals as nucleating centers [49].

The crystal patterns of neat PLLA and the $\mathrm{mHA}_{1-3} /$ PLA nanocomposites were characterized (Figure 7). The diffraction peaks for neat PLLA at $2 \theta=16.8^{\circ}$ and $19.0^{\circ}$ were attributed to the characteristic peaks of the $\beta$ crystal corresponding to the $(200 / 110)$ and (203) crystal planes, respectively. The peak intensities indicate that the obtained samples have good crystallinity. For the $\mathrm{mHA}_{1-3} /$ PLA nanocomposites, the characteristic peaks of the $\beta$ crystals and the stereocomplex (sc) crystals existed simultaneously. The diffraction peaks at $2 \theta=11.6^{\circ}, 20.8^{\circ}$, and $23.9^{\circ}$ were attributed to $s c$ crystallites and corresponded to the (110), (300)/(030), and (220) lattice planes, respectively. The formation of sc crystals was due to the stereocomplex interactions between the PDLA grafted onto the surface of $\mathrm{mHA}_{1-3}$ and the PLLA matrix. The sc crystals simultaneously acted as nucleation sites to promote the crystallization of PLLA.

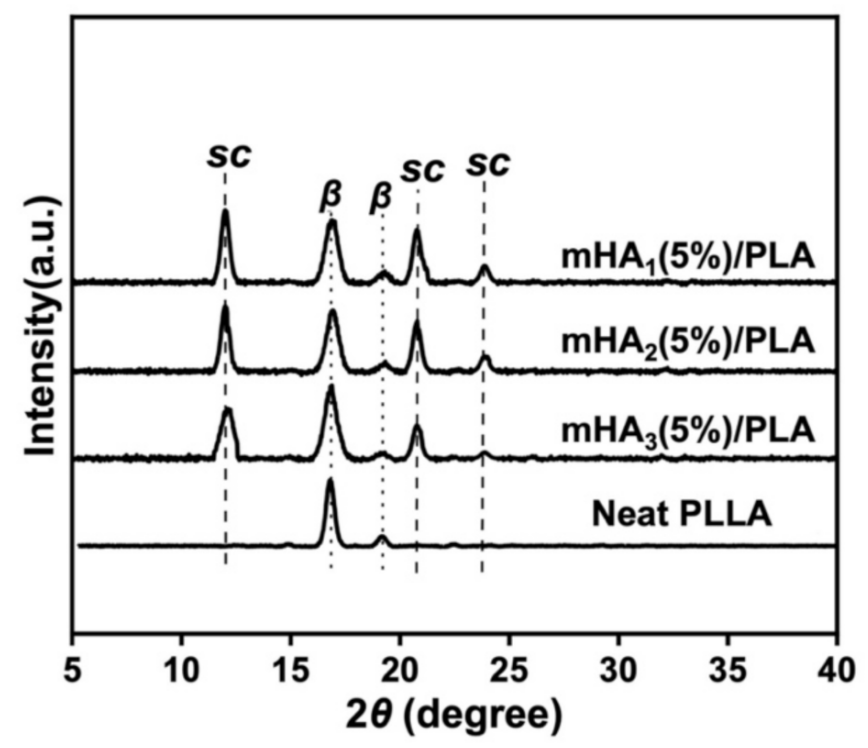

Figure 7. XRD spectra of PLLA and the $\mathrm{mHA}_{1-3} /$ PLA composite.

Because crystallization has a significant influence on the mechanical properties of materials, the kinetics of the non-isothermal crystallization of the nanocomposites were 
investigated at varied heating rates (Figure 8). With an increasing heating rate, the peak crystallization temperatures $\left(T_{p}\right)$ of all the materials shifted toward higher temperatures and the exothermic peaks became wide This was due to the gradual increase in the formation of imperfect crystals during crystallization [50,51]. At the same heating rate, the $T_{p}$ values of the $\mathrm{mHA}_{1-3} /$ PLA nanocomposites were lower than that of the neat PLLA, indicating that the addition of $\mathrm{mHA}_{1-3}$ effectively promoted the cold crystallization nucleation of the PLLA matrix.
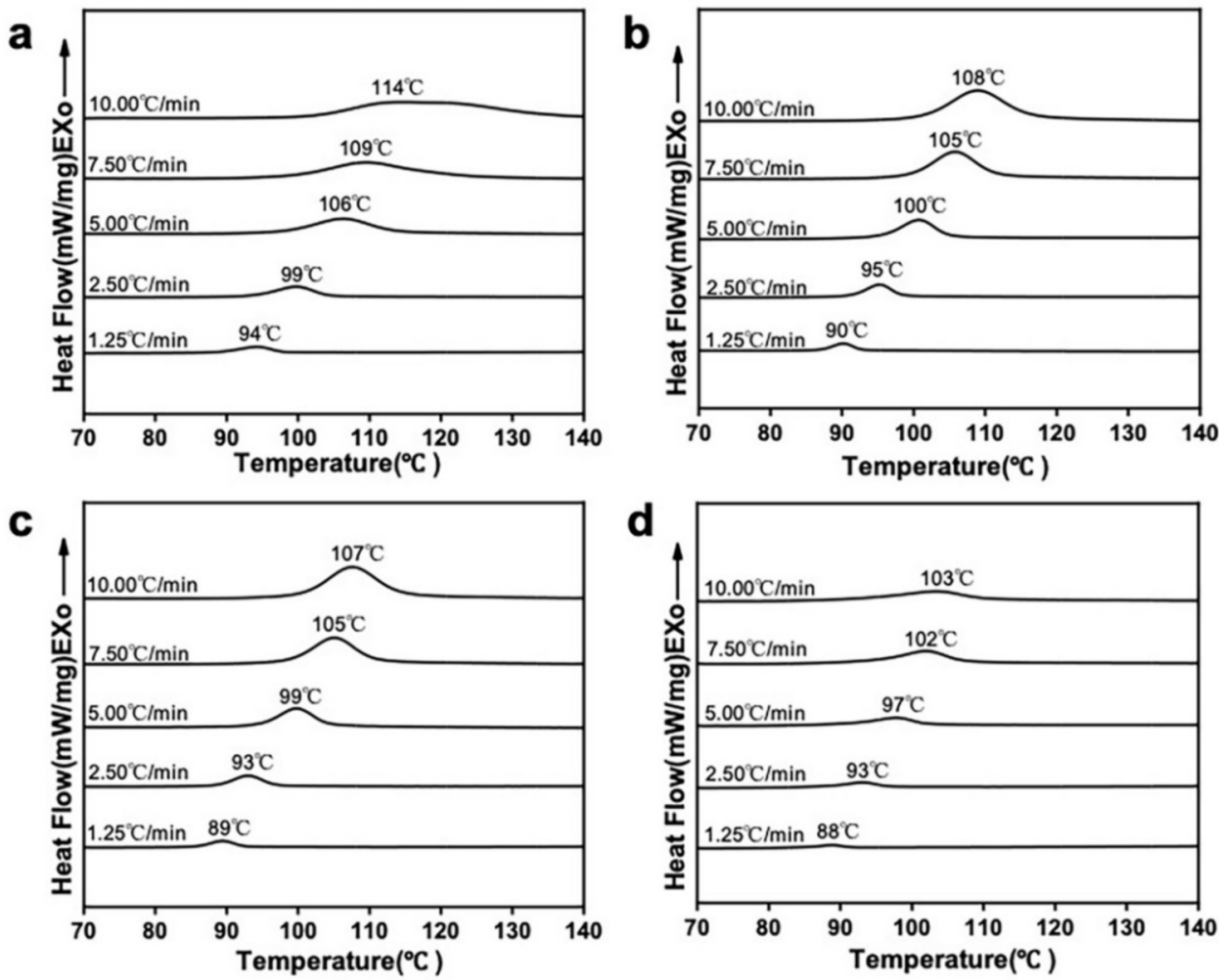

Figure 8. Heat flux curves of PLLA and the $\mathrm{mHA}_{1-3} / \mathrm{PLA}$ composites at various temperatures: (a) PLLA; (b) $\mathrm{mHA}_{1}(5 \%) /$ PLA; (c) $\mathrm{mHA}_{2}(5 \%) / \mathrm{PLA}$; (d) $\mathrm{mHA}_{3}(5 \%) / \mathrm{PLA}$.

The relative crystallinities of PLLA and the $\mathrm{mHA}_{1-3} / \mathrm{PLA}$ nanocomposites were plotted against the temperature at different heating rates (Figure 9). All the curves were S-shaped, indicating that the crystallization of the materials could be divided into three stages: the slow nucleation stage, the fast primary nucleation stage and the slow secondary nucleation stag Moreover, all the curves shifted to higher temperatures at a higher heating rate, indicating that the acceleration of the heating rate makes the samples not have enough time to form the crystal nuclei.

The relative crystallinity versus time at different heating rates was also investigated (Figure 10). The curves gradually shifted to the left at higher heating rate The half crystallization times $\left(t_{1 / 2}\right)$ values of PLA and the $\mathrm{mHA}_{1-3} /$ PLA nanocomposites decreased with the increasing heating rate (Table 2). Moreover, at the same heating rate, the $t_{1 / 2}$ values of the $\mathrm{mHA}_{1-3} /$ PLA nanocomposites were lower than that of PLA, indicating that $\mathrm{mHA}_{1-3}$ can promote heterogeneous nucleation and improve the crystallization of the PLA main chain. 
a

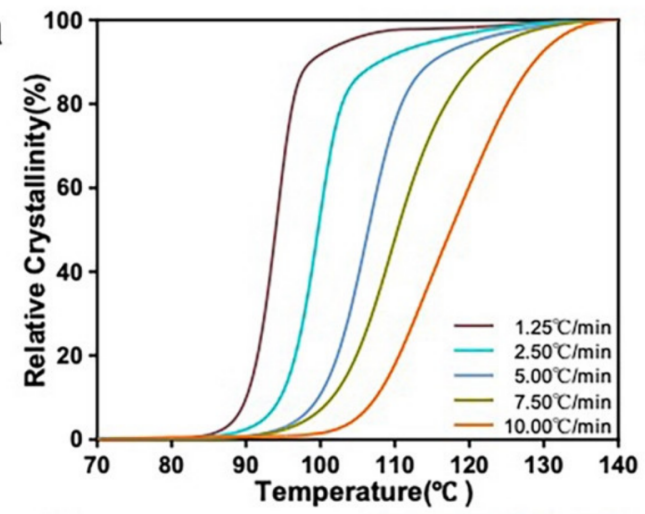

c

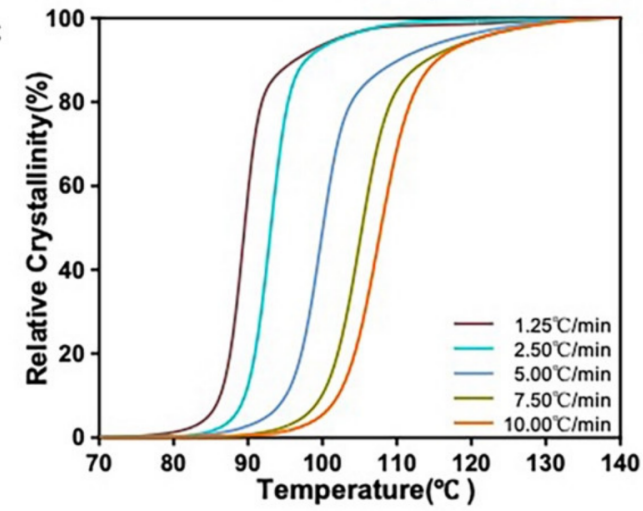

b

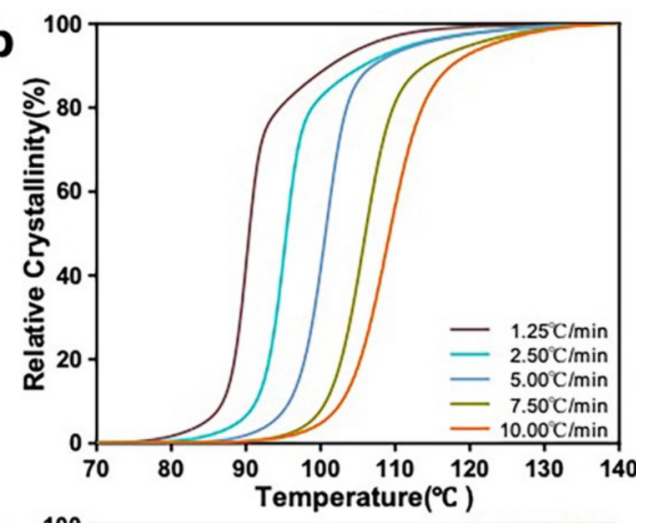

d

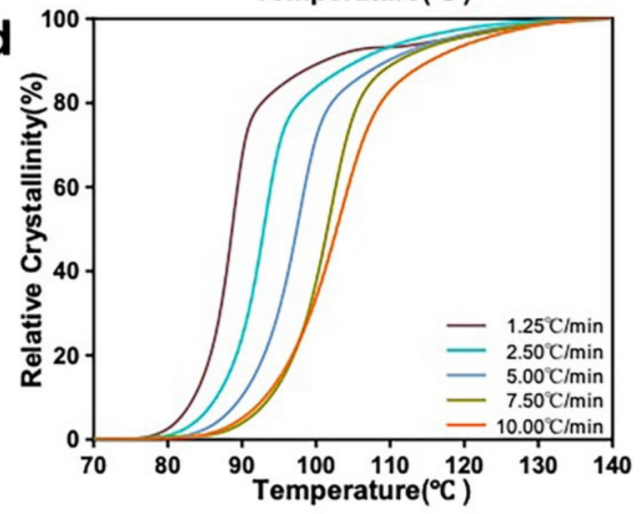

Figure 9. Relative crystallinity curves of PLLA and the $\mathrm{mHA}_{1-3} / \mathrm{PLA}$ composites at various temperatures: (a) PLLA; (b) $\mathrm{mHA}_{1}(5 \%) / \mathrm{PLA}$; (c) $\mathrm{mHA}_{2}(5 \%) / \mathrm{PLA}$; (d) $\mathrm{mHA}_{3}(5 \%) / \mathrm{PLA}$.
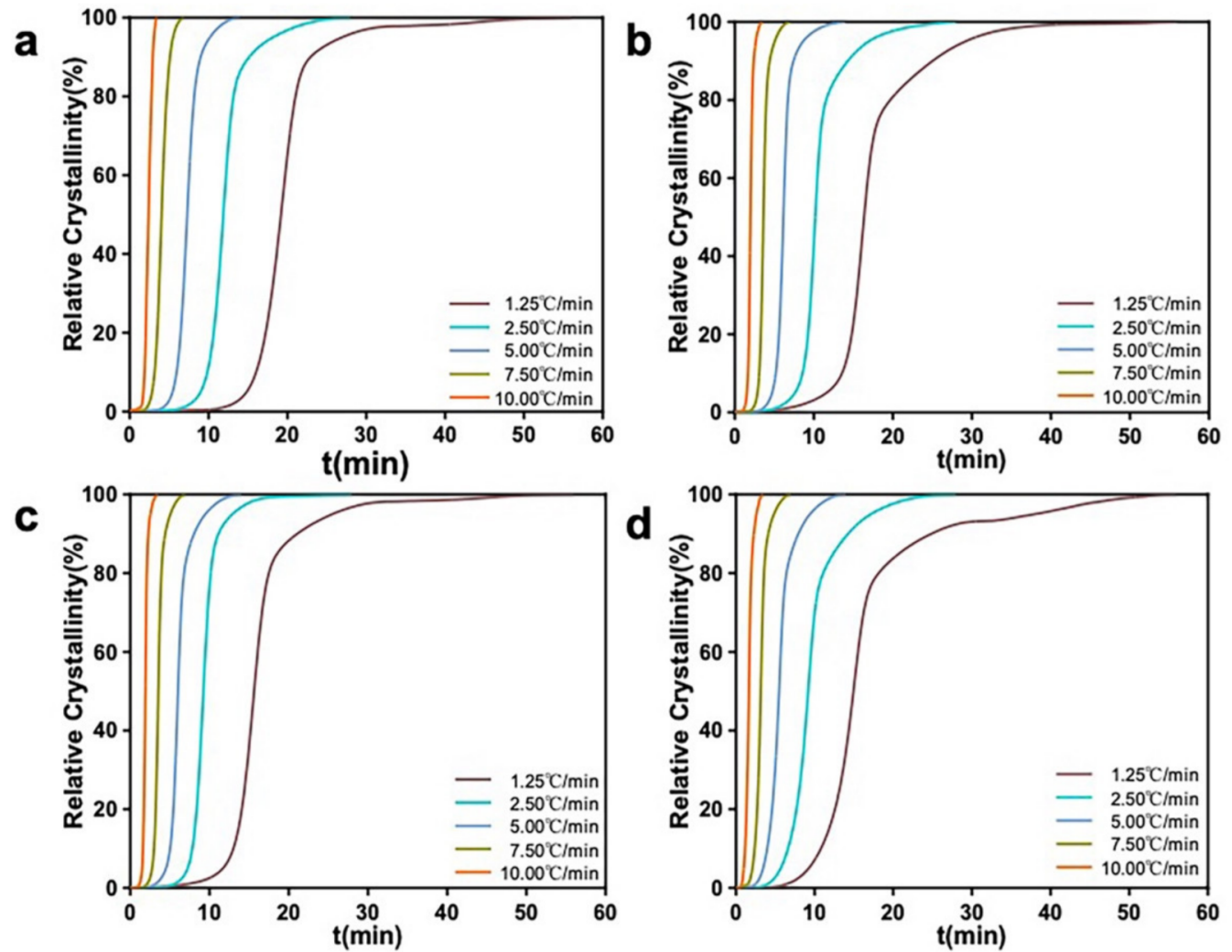

Figure 10. Relative crystallinity curves of PLLA and the $\mathrm{mHA}_{1-3} / \mathrm{PLA}$ composites over time: (a) PLLA; (b) $\mathrm{mHA}_{1}(5 \%) / \mathrm{PLA}$; (c) $\mathrm{mHA}_{2}(5 \%) / \mathrm{PLA}$; (d) $\mathrm{mHA}_{3}(5 \%) / \mathrm{PLA}$. 
Table 2. Semi-crystallization times of PLLA and the $\mathrm{HA}_{1-3} /$ PLA nanocomposites at different heating rate.

\begin{tabular}{cccccc}
\hline Samples & $\mathbf{1 . 2 5}{ }^{\circ} \mathbf{C} / \mathbf{m i n}$ & $\mathbf{2 . 5 0}{ }^{\circ} \mathbf{C} / \mathbf{m i n}$ & $\mathbf{5 . 0 0}{ }^{\circ} \mathbf{C} / \mathbf{m i n}$ & $\mathbf{7 . 5 0}{ }^{\circ} \mathbf{C} / \mathbf{m i n}$ & $\mathbf{1 0 . 0 0}{ }^{\circ} \mathbf{C} / \mathbf{m i n}$ \\
\hline PLLA & 19.16 & 11.87 & 7.31 & 4.08 & 2.39 \\
$\mathrm{mHA}_{1} /$ PLA & 16.43 & 10.14 & 6.16 & 3.56 & 2.00 \\
$\mathrm{mHA}_{2}$ /PLA & 15.62 & 9.27 & 5.98 & 3.48 & 1.87 \\
$\mathrm{mHA}_{3}$ /PLA & 14.99 & 9.15 & 5.51 & 3.15 & 1.64 \\
\hline
\end{tabular}

$t_{1 / 2}$ : Semi-crystallization time, $\min$.

The crystallization parameters were calculated using (5) and (6) (Table 3). $\mathrm{n}_{1}$ and $Z_{\mathrm{c} 1}$ are the parameters of the primary crystallization stage, while $\mathrm{n}_{2}$ and $\mathrm{Z}_{\mathrm{c} 2}$ are the parameters of the secondary crystallization stag The $\mathrm{n}_{1}$ value range of neat PLLA was 3.61-6.93 and the $\mathrm{n}_{1}$ value range of the $\mathrm{mHA}_{1-3}$ /PLA nanocomposites was 3.20-8.49, indicating that the crystal growth mode involved simultaneous two-dimensional and three-dimensional growth.

Table 3. Avrami indices (n) and crystallization rate constants $(\mathrm{K}(\mathrm{T}))$ of PLLA and the $\mathrm{mHA}_{1-3} /$ PLA nanocomposites at different heating rate.

\begin{tabular}{|c|c|c|c|c|c|c|}
\hline Samples & Avrami & $\begin{array}{c}1.25 \\
{ }^{\circ} \mathrm{C} / \mathrm{min}\end{array}$ & $\begin{array}{c}2.50 \\
{ }^{\circ} \mathrm{C} / \mathrm{min}\end{array}$ & $\begin{array}{c}5.00 \\
{ }^{\circ} \mathrm{C} / \mathrm{min}\end{array}$ & $\begin{array}{c}7.50 \\
{ }^{\circ} \mathrm{C} / \mathrm{min}\end{array}$ & $\begin{array}{c}10.00 \\
{ }^{\circ} \mathrm{C} / \mathrm{min}\end{array}$ \\
\hline \multirow{4}{*}{ Neat PLLA } & $\mathrm{n}_{1}$ & 3.61 & 4.44 & 5.43 & 6.65 & 6.93 \\
\hline & $Z_{\mathrm{c} 1}$ & 4.29 & 4.25 & 4.05 & 3.25 & 1.8 \\
\hline & $\mathrm{n}_{2}$ & 1.15 & 2.06 & 2.78 & 3.27 & 4.24 \\
\hline & $\mathrm{Z}_{\mathrm{c} 2}$ & 1.19 & 1.12 & 0.98 & 0.84 & 0.57 \\
\hline \multirow{4}{*}{$\mathrm{mHA}_{1} / \mathrm{PLA}$} & $\mathrm{n}_{1}$ & 3.41 & 3.96 & 4.66 & 6.35 & 8.17 \\
\hline & $Z_{\mathrm{c} 1}$ & 4.54 & 4.42 & 4.2 & 3.94 & 2.62 \\
\hline & $\mathrm{n}_{2}$ & 1.42 & 1.69 & 1.9 & 2.52 & 3.15 \\
\hline & $\mathrm{Z}_{\mathrm{c} 2}$ & 1.62 & 1.6 & 1.31 & 1.29 & 0.85 \\
\hline \multirow{4}{*}{$\mathrm{mHA}_{2} / \mathrm{PLA}$} & $\mathrm{n}_{1}$ & 3.2 & 3.93 & 4.77 & 6.29 & 8.49 \\
\hline & $\mathrm{Z}_{\mathrm{c} 1}$ & 4.42 & 4.5 & 4.16 & 3.85 & 2.6 \\
\hline & $\mathrm{n}_{2}$ & 1.13 & 1.29 & 2.08 & 2.52 & 2.85 \\
\hline & $Z_{\mathrm{c} 2}$ & 1.23 & 0.95 & 1.54 & 1.29 & 0.68 \\
\hline \multirow{4}{*}{$\mathrm{mHA}_{3} / \mathrm{PLA}$} & $\mathrm{n}_{1}$ & 3.59 & 4.43 & 4.14 & 4.98 & 5.38 \\
\hline & $\mathrm{Z}_{\mathrm{c} 1}$ & 4.62 & 4.55 & 3.38 & 2.76 & 1.31 \\
\hline & $\mathrm{n}_{2}$ & 1.11 & 1.7 & 1.93 & 2.14 & 2.5 \\
\hline & $\mathrm{Z}_{\mathrm{c} 2}$ & 1.21 & 1.6 & 1.38 & 0.98 & 0.53 \\
\hline
\end{tabular}

$\mathrm{Z}_{\mathrm{c} 1}$ : primary crystallization rate constant; $\mathrm{Z}_{\mathrm{c} 2}$ : secondary crystallization rate constant; $\mathrm{n}_{1}$ : Avrami index of primary crystallization; $\mathrm{n}_{2}$ : Avrami index of secondary crystallization.

In addition, the $\mathrm{n}_{1}$ values of all samples increased with the increasing heating rate and the $n_{2}$ values were lower than the $n_{1}$ value This was due to a change in the growth mode of the crystals during the secondary crystallization stag Secondary crystallization involves the perfection of crystals, including the elimination of defects and the melting/recrystallization of small crystal The $Z_{c 1}$ and $Z_{c 2}$ values of PLLA and the $\mathrm{mHA}_{1-3} / \mathrm{PLA}$ nanocomposites decreased with increasing heating rate and the $Z_{c 1}$ and $Z_{c 2}$ values of the nanocomposites were larger than those of the PLLA. These results confirm that the addition of $\mathrm{mHA}_{1-3}$ improved the crystallization rate of the PLLA matrix.

The $\mathrm{mHA}_{1} /$ PLA and $\mathrm{mHA}_{2} / \mathrm{PLA}$ nanocomposites exhibited similar crystallization kinetic This was attributed to the minor difference in morphology and size between $\mathrm{mHA}_{1}$ and $\mathrm{mHA}_{2}$. Therefore, their kinetic effects on the crystallization behavior of the matrix were simila However, the $\mathrm{mHA}_{3} / \mathrm{PLA}$ nanocomposite displayed a different crystallization behavio This was attributed the irregular, quadrilateral shape of $\mathrm{mHA}_{3}$, which was also multilayered, leading to a stronger anisotropic effect. By reducing the specific surface area, $\mathrm{mHA}_{3}$ plays a different role from $\mathrm{mHA}_{1}$ and $\mathrm{mHA}_{2}$ due to its unique propertie 
The in vitro biocompatibility of $\mathrm{mHA}_{1-3}$ was evaluated briefly in terms of hemolytic ratio and cytotoxicity (Figure 11). The red blood cells in the DI water group were found almost completely ruptured, and those in other groups were deposited at the bottom of the centrifuge tube (Figure 11b). No significant difference between the $\mathrm{mHA}_{1-3}$ group and the PBS group could be observed, indicating that the red blood cells were intact. Quantitative analysis evidenced hemolysis ratios lower than $5 \%$ in the case of nanoparticles at different concentrations, indicating that the $\mathrm{mHA}_{1-3}$ does not cause obvious hemolysis and has appreciable hemocompatibility.
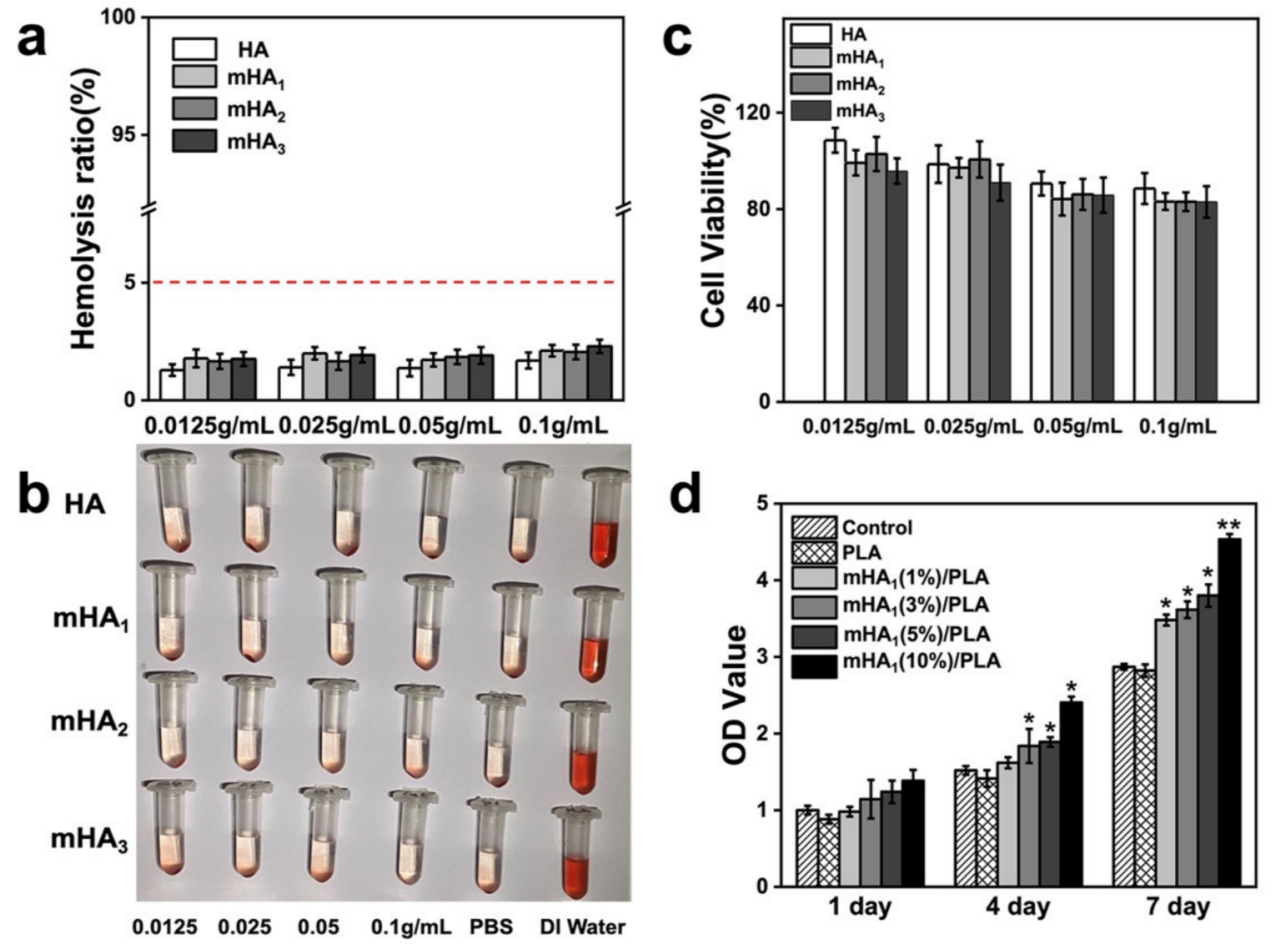

Figure 11. Biocompatibility of nanoparticles and nanocomposites: $(\mathbf{a}, \mathbf{b})$, hemolysis test; (c) cytotoxicity test; (d) the proliferation of rMSCs on composite surfac * refers to $p<0.05,{ }^{* *}$ refers to $p<0.01$.

The cytotoxicity of materials is of primary importance (Figure 11c). In this case, it was found that the cell survival rate decreased slightly at higher concentration of nanoparticles; however, it was still higher than $80 \%$ at the concentration of nanoparticles of $0.1 \mathrm{~g} / \mathrm{mL}$, suggesting an acceptable cytotoxicity of these nanoparticles at high concentration. It was also observed that there were no significant difference between different groups, which further proved the cytocompatibility of the $\mathrm{mHA}_{1-3}$ nanoparticle

The proliferation of rMSCs, cultured on the surface of $\mathrm{mHA}_{1} / \mathrm{PLA}$ films with varied concentrations of $\mathrm{mHA}_{1}$, was measured as a function of culture time (Figure 11d). In general, the cells in each group proliferated significantly with tim Compared with these on the surface of the neat PLA film, the rMSCs cultured on $\mathrm{mHA}_{1} / \mathrm{PLA}$ film demonstrated better cell proliferation, and the $\mathrm{mHA}_{1}(10 \%) / \mathrm{PLA}$ group demonstrated higher proliferation when the cells were cultured at day 7 . The above results indicated that the nanocomposite films have better performance in supporting the proliferation of rMSC

The calcium nodules formed by $\mathrm{rMSC}$ on the $\mathrm{mHA}_{1} /$ PLA films were visualized through ARS staining, and the calcium deposition was quantified (Figure 12a-c). It was found that when the rMSCs were cultured for 7, 14 and 21 days, red spots appeared in the ARS-stained samples and a clear color progression gradient with culture time was observed. Compared with that on the neat PLA, more red spots on the surface of the nanocomposite films could be observed (Figure 12a,b); quantitative analysis also demonstrated a significantly increased calcium deposition on the nanocomposite films, 
suggesting that the nanocomposite can promote mineralization of rMSCs (Figure 12c). The $\mathrm{mHA}_{1}(5 \%) / \mathrm{PLA}$ and $\mathrm{mHA}_{1}(10 \%) /$ PLA nanocomposite films exhibited significantly higher calcium deposition levels than other film These results demonstrate that high concentration of $\mathrm{mHA}_{1}$ can promote the mineralization of rMSC

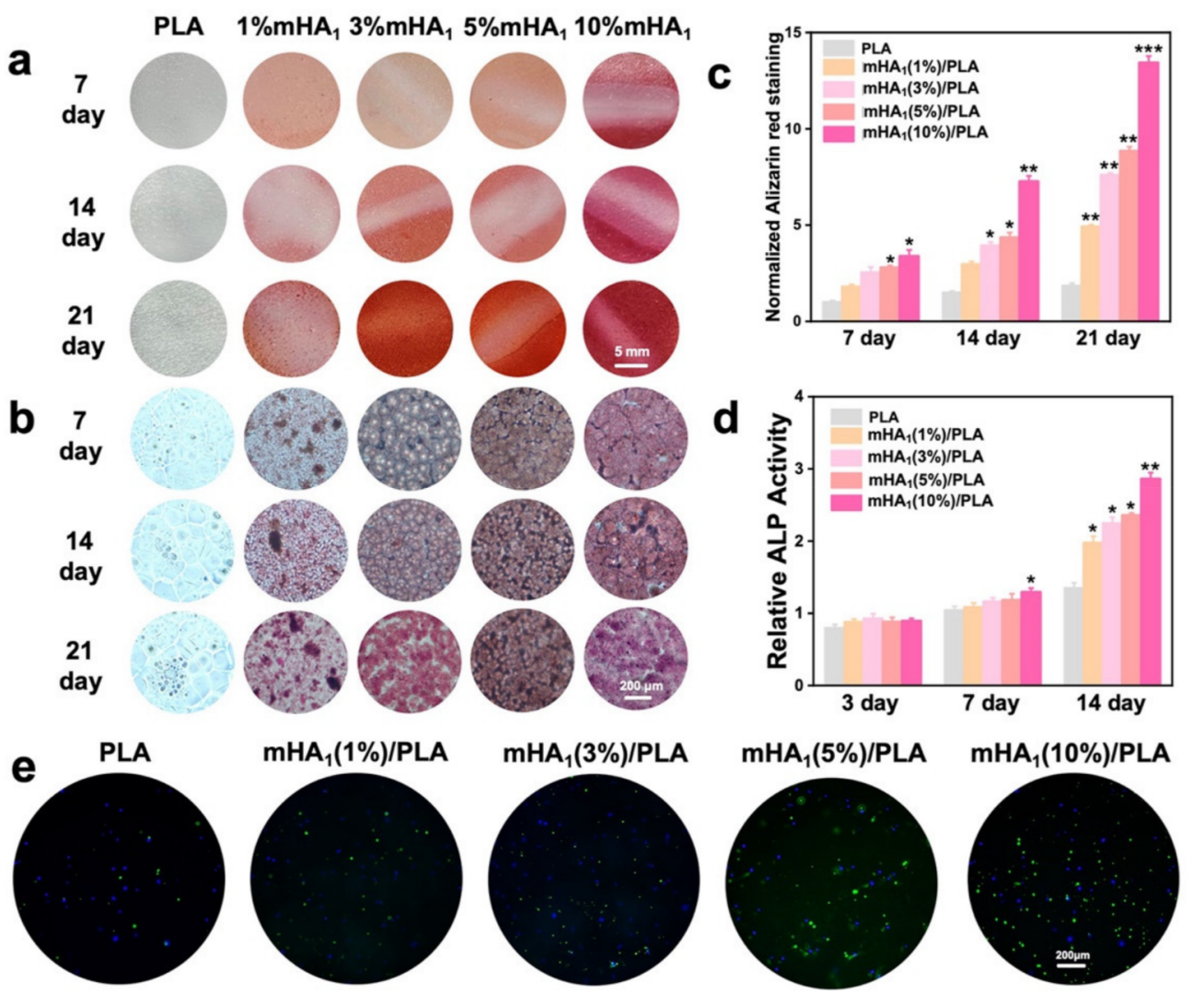

Figure 12. The expression of osteogenic markers of rMSCs on the surface of the composite: (a) ARstaining digital photos; (b) AR-staining light microscopy; (c) quantitative analysis by AR staining; (d) ALP activity; (e) the expression of osteocalcin (OCN: green fluorescence, nucleus: blue fluorescence). ${ }^{*}$ refers to $p<0.05,{ }^{* *}$ refers to $p<0.01$ and ${ }^{* * *}$ refers to $p<0.001$.

The ALP activity of rMSCs on the surface of $\mathrm{mHA}_{1} /$ PLA was assayed (Figure $12 \mathrm{~d}$ ). Higher level of ALP activity was achieved on the $\mathrm{mHA}_{1}(10 \%) / \mathrm{PLA}$ film than the other groups after 7 days of cultur After 14 days of culture, the $\mathrm{mHA}_{1} / \mathrm{PLA}$ composite group demonstrated elevated ALP activity compared with the PLA group, and the $\mathrm{mHA}_{1}$ $(10 \%) /$ PLA group demonstrated the highest ALP activity among these group Thus, rMSCs grown on nanocomposite films containing $\mathrm{mHA}_{1}$ would yield higher levels of ALP expression.

The expression of OCN was evidenced by immunofluorescence staining (Figure 12e). A stronger fluorescence intensity (green fluorescence) was measured for $\mathrm{mHA}_{1} / \mathrm{PLA}$ nanocomposite films compared with that of PLA. In addition, a significant increase in fluorescence intensity was observed with increasing $\mathrm{mHA}_{1}$ content, suggesting that the presence of $\mathrm{mHA}_{1}$ may promote the expression of OCN in rMSC

The spreading of rMSCs on neat PLA and $\mathrm{mHA}_{1} / \mathrm{PLA}$ nanocomposite films was observed under CLSM (Figure 13). Although the cells spread on the surface of neat PLA, the spreading area of the cells was quite limited, and actin stress fibers were poorly developed. The F-actin plays a crucial role in cell spreading, and there is a direct correlation between poor cell spreading and low cell viability on the surface of PLA. Significantly better cell spreading and higher amounts of actin filaments on the surface of $\mathrm{mHA}_{1} /$ PLA films were observed compared with those on the neat PLA film. A higher content of $\mathrm{mHA}_{1}$ seemed to favor the cell spreading and adhesion. These findings, in addition to the above 
osteogenic differentiation assays, clearly suggest that the mHA/PLA nanocomposites can be used as excellent candidate materials in potential bone repair application

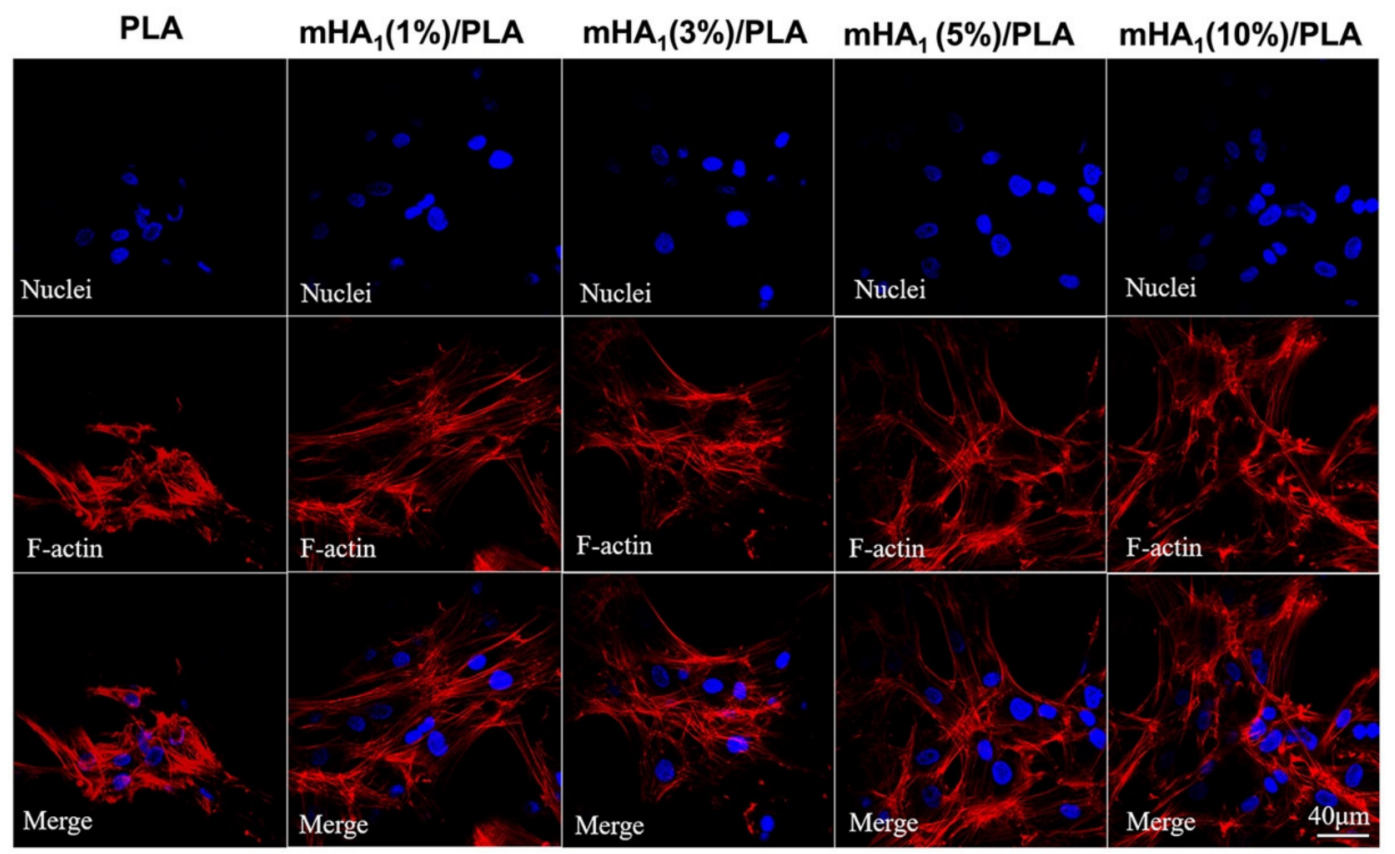

Figure 13. Spreading of rMSCs on surface of nanocomposite film.

\section{Conclusions}

In this study, stereocomplexation-reinforced high-strength mHA/PLA composite is prepared to investigate its mechanical properties and bone repair potential. In detail, the addition of mHA increased the tensile strength, the Young's modulus, the interfacial shear strength, the elongation-at-break and the crystallinity of PLA by $34 \%, 53 \%, 26 \%$, $70 \%$ and $17 \%$, respectively. Benefiting from the stereocomplexation and the structural similarity between PDLA and PLLA, enhanced the interfacial interaction between n-HA and PLLA as well as improved the dispersion of n-HA in the PLLA matrix were achieved through surface grafting of PDLA; in addition, the stereocomplex crystals formed by the stereocomplexation of PDLA and PLLA also acted as the nucleating agents to facilitate the crystallization of the PLLA matrix. The improved dispersion of the nanofiller, enhanced interfacial interaction between the nano-filler and matrix and the elevated crystallinity of the matrix synergistically contribute to the greatly increased mechanical properties of the PLLA nanocomposit A study of crystallization kinetics demonstrates that $\mathrm{mHA}_{1} / \mathrm{PLA}$ and $\mathrm{mHA}_{2} /$ PLA nanocomposites display similar crystallization kinetics and that the addition of mHA significantly increases the crystallization rate of the matrix. An in vitro cytotoxicity assay and the osteogenic differentiation of rMSCs revealed that the $\mathrm{mHA}_{1} / \mathrm{PLA}$ composite is cytocompatible, and can effectively induce apatite precipitation and support the adhesion, proliferation and osteogenic differentiation of rMSC These mHA/PLA nanocomposites can be used as excellent candidate materials in potential bone repair application.

Author Contributions: Writing-original draft preparation, N.G. and Z.W.; formal analysis, N.G.; investigation, N.G., M.Z., S.L. and J.H.; methodology, C.Z.; writing-review and editing, C.Z. and Z.W.; supervision, C.Z. and Z.W. All authors have read and agreed to the published version of the manuscript.

Funding: This research was funded by the National Key Research and Development Program of China (Grant N: 2018YFB1105701) from the Ministry of Science and Technology of the People's Republic of China, the National Natural Science Fund (Grant No: 81971760, 81801845) from the National 
Natural Science Foundation of China and the Shenzhen Fundamental Research Program (Grant N: JCYJ20190807160811355) from the Shenzhen Science and Technology Innovation Commission.

Institutional Review Board Statement: The animal study protocol was approved by the Institutional Animal Care and Use Committee (IACUC), Sun Yat-Sen University (Approval N: SYSU-IACUC-2022000101 and Approval Date: 21 January 2022).

Data Availability Statement: Not applicable.

Conflicts of Interest: The authors declare no conflict of interest.

\section{Appendix A}

\section{Silanization of reaction vessel}

Trimethylchlorosilane was added to anhydrous toluene to prepare a solution at a concentration of $20 \%$ ( $\mathrm{vol} / \mathrm{vol})$. The glass ampoule used for polymerization was treated with chromic acid solution overnight, washed with distilled water for five times and dried at $120^{\circ} \mathrm{C}$, filled with the above solution, sealed and incubated at room temperature for three hour Then, the ampoule was washed alternately with small amount of methanol and toluene three times, dried at $120^{\circ} \mathrm{C}$ and stored in a desiccator before us

\section{Synthesis of schistose n-HA}

A total of $0.50 \mathrm{~g}$ of sodium dodecyl sulfonate in $15 \mathrm{~mL}$ of DI was mixed with $30 \mathrm{~mL}$ of absolute ethanol in a three-neck flask and stirred at $60{ }^{\circ} \mathrm{C}$ until a transparent solution (Solution A) was achieved. A total of $11.80 \mathrm{~g}$ of $\mathrm{Ca}\left(\mathrm{NO}_{3}\right)_{2} \cdot 4 \mathrm{H}_{2} \mathrm{O}$ was added to $15 \mathrm{~mL}$ of DI, stirred at $60{ }^{\circ} \mathrm{C}$ until transparent and then added to Solution A. A total of $3.96 \mathrm{~g}$ $\left(\mathrm{NH}_{4}\right)_{2} \mathrm{HPO}_{4}$ in $30 \mathrm{~mL}$ of DI was mixed with $30 \mathrm{~mL}$ of absolute ethanol, then stirring rapidly to ensure no precipitation occurred. This solution was then quickly poured into the above reaction solution. Subsequently, $2.00 \mathrm{~g}$ of $\mathrm{NaOH}$ in $40 \mathrm{~mL}$ of DI/ethanol mixture solvent $(\mathrm{vol} / \mathrm{vol}=1: 1)$ was poured into the reaction mixture solution. The reaction was refluxed at $83^{\circ} \mathrm{C}$ for $4 \mathrm{~h}$, and stayed at room temperature over $12 \mathrm{~d}$ to allow the deposition of schistose n-HA; the precipitate was washed several times with DI and collected by centrifuging.
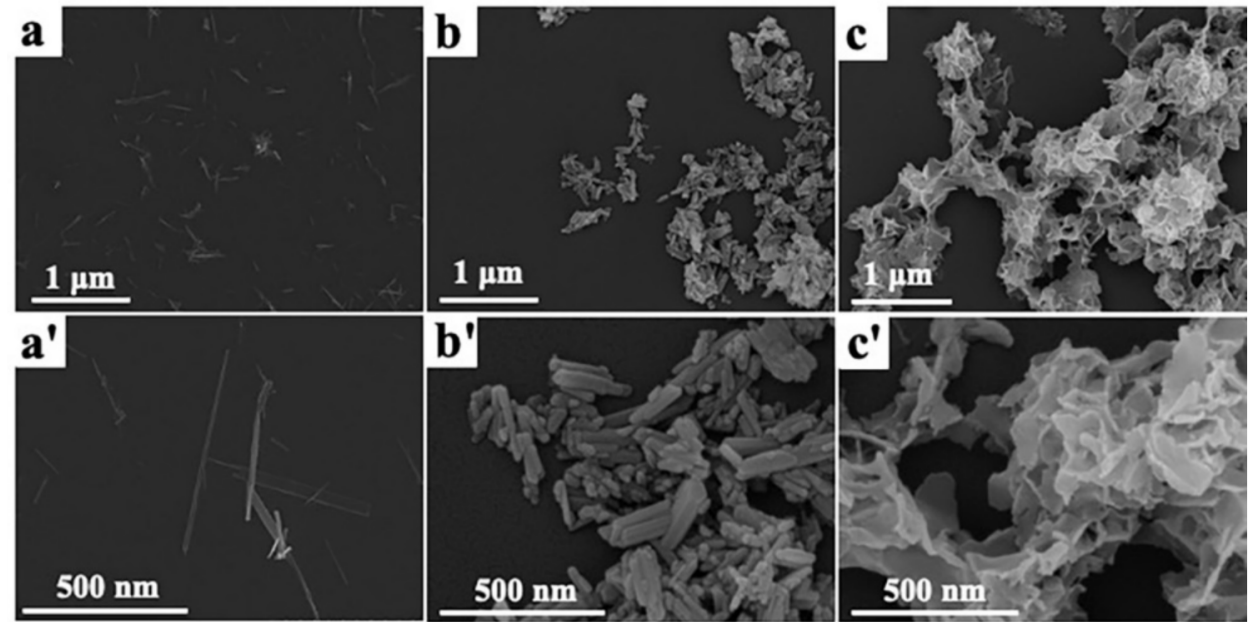

Figure A1. SEM images of n-HA: $\left(\mathbf{a}, \mathbf{a}^{\prime}\right)$, acicular n-HA; $\left(\mathbf{b}, \mathbf{b}^{\prime}\right)$, clavate n-HA; $\left(\mathbf{c}, \mathbf{c}^{\prime}\right)$, schistose n-HA.

\section{References}

1. Régibeau, N.; Tilkin, G.; Grandfils, C.; Heinrichs, B. Preparation of Poly-D, L-lactide Based Nanocomposites with Polymer-grafted Silica by Melt Blending: Study of Molecular, Morphological, and Mechanical Propertie. Polym. Compos. 2021, 42, 955-972. [CrossRef]

2. Fortunati, E.; Luzi, F.; Puglia, D.; Petrucci, R.; Kenny, J.M.; Torre, L. Processing of PLA Nanocomposites with Cellulose Nanocrystals Extracted from Posidonia Oceanica Waste: Innovative Reuse of Coastal Plant. Ind. Crop. Prod. 2015, 67, 439-447. [CrossRef] 
3. Agrawal, M.; Ray, B. Biodegradable Polymeric Scaffolds for Musculoskeletal Tissue Engineering. J. Biomed. Mater. Res. 2001, 55, 141-150. [CrossRef]

4. Hrubovcakova, M.; Kupkova, M.; Dzupon, M.; Giretova, M.; Medvecky, L.; Dzunda, M. Biodegradable Polylactic Acid and Polylactic Acid/Hydroxyapatite Coated Iron Foams for Bone Replacement Material. Int. J. Electrochem. Sci. 2017, 12, 11122-11136. [CrossRef]

5. Shady, F.; Daniel, G.A.; Robert, L. Physical and mechanical properties of PLA, and their functions in widespread applications -A comprehensive review. Adv. Drug Deliv. Rev. 2016, 107, 367-392.

6. Oh, S.H.; Lee, J.H. Hydrophilization of Synthetic Biodegradable Polymer Scaffolds for Improved Cell/Tissue Compatibility. Biomed. Mater. 2013, 8, 014101. [CrossRef] [PubMed]

7. Rasal, M.; Janorkar, A.V.; Hirt, D.E. Poly(Lactic Acid) Modification. Prog. Polym. Sci. 2010, 35, 338-356. [CrossRef]

8. Bohner, M.; Miron, J. A Proposed Mechanism for Material-Induced Heterotopic Ossification. Mater. Today 2019, 22, 132-141. [CrossRef]

9. Wang, W.; Zhang, B.; Li, M.; Li, J.; Zhang, H.Y.; Wang, L.; Wang, K.; Zhou, L.L.; Fan, Y.; Zhang, X. 3D Printing of PLA/n-HA Composite Scaffolds with Customized Mechanical Properties and Biological Functions for Bone Tissue Engineering. Compos. Part B Eng. 2021, 224, 109192. [CrossRef]

10. Cao, H.; Kuboyama, N. A Biodegradable Porous Composite Scaffold of PGA/Beta-TCP for Bone Tissue Engineering. Bone 2010, 46, 386-395. [CrossRef] [PubMed]

11. Dorozhkin, S.V. Calcium Orthophosphate Coatings on Magnesium and Its Biodegradable Alloy. Acta Biomater. 2014, 10, $2919-2934$. [CrossRef]

12. Fu, S.; Ni, P.; Wang, B.; Chu, B.; Zheng, L.; Luo, F.; Luo, J.; Qian, Z. Injectable and Thermo-Sensitive PEG-PCL-PEG Copolymer/Collagen/n-HA Hydrogel Composite for Guided Bone Regeneration. Biomaterials 2012, 33, 4801-4809. [CrossRef] [PubMed]

13. Ali, W.; Mehboob, A.; Han, M.-G.; Chang, S.-H. Novel Biodegradable Hybrid Composite of Polylactic Acid (PLA) Matrix Reinforced by Bioactive Glass (BG) Fibres and Magnesium (Mg) Wires for Orthopaedic Application. Compos. Struct. 2020, 245, 112322. [CrossRef]

14. Barradas, A.M.; Fernandes, H.A.M.; Groen, N.; Chai, Y.; Schrooten, J.; van de Peppel, J.; van Leeuwen, J.P.T.M.; van Blitterswijk, A.; de Boer, J. A Calcium-Induced Signaling Cascade Leading to Osteogenic Differentiation of Human Bone Marrow-Derived Mesenchymal Stromal Cell. Biomaterials 2012, 33, 3205-3215. [CrossRef] [PubMed]

15. Shih, Y.-V.; Hwang, Y.; Phadke, A.; Kang, H.; Hwang, N.S.; Caro, E.J.; Nguyen, S.; Siu, M.; Theodorakis, E.A.; Gianneschi, N.; et al. Calcium Phosphate-Bearing Matrices Induce Osteogenic Differentiation of Stem Cells through Adenosine Signaling. Proc. Natl. Acad. Sci. 2014, 111, 990-995. [CrossRef]

16. Wang, Y.-K.; Yu, X.; Cohen, D.M.; Wozniak, M.A.; Yang, M.T.; Gao, L.; Eyckmans, J.; Chen, S. Bone Morphogenetic Protein-2Induced Signaling and Osteogenesis Is Regulated by Cell Shape, RhoA/ROCK, and Cytoskeletal Tension. Stem Cells Dev. 2012, 21, 1176-1186. [CrossRef]

17. Lian, J.B.; Stein, G.S.; Javed, A.; van Wijnen, A.J.; Stein, J.L.; Montecino, M.; Hassan, M.Q.; Gaur, T.; Lengner, J.; Young, D.W. Networks and Hubs for the Transcriptional Control of Osteoblastogenesi. Rev. Endocr Metab Disord 2006, 7, 1-16. [CrossRef] [PubMed]

18. Okada, S.; Ito, H.; Nagai, A.; Komotori, J.; Imai, H. Adhesion of Osteoblast-like Cells on Nanostructured Hydroxyapatit. Acta Biomater. 2010, 6, 591-597. [CrossRef] [PubMed]

19. Ricotti, L.; Taccola, S.; Pensabene, V.; Mattoli, V.; Fujie, T.; Takeoka, S.; Menciassi, A.; Dario, P. Adhesion and Proliferation of Skeletal Muscle Cells on Single Layer Poly(Lactic Acid) Ultra-Thin Film. Biomed. Microdevices 2010, 12, 809-819. [CrossRef]

20. Wang, K.; Zhou, C.; Hong, Y.; Zhang, X. A Review of Protein Adsorption on Bioceramic. Interface Focu 2012, 2, 259-277. [CrossRef]

21. Xu, X.; Chen, X.; Liu, A.; Hong, Z.; Jing, X. Electrospun Poly(L-Lactide)-Grafted Hydroxyapatite/Poly(L-Lactide) Nanocomposite Fiber. Eur. Polym. J. 2007, 43, 3187-3196. [CrossRef]

22. Toledano, M.; Osorio, R.; Vallecillo-Rivas, M.; Osorio, E.; Lynch, D.; Aguilera, F.S.; Toledano, R.; Sauro, S. Zn-Doping of Silicate and Hydroxyapatite-Based Cements: Dentin Mechanobiology and Bioactivity. J. Mech. Behav. Biomed. Mater. 2021, 114, 104232. [CrossRef] [PubMed]

23. Fernando, D.; Attik, N.; Pradelle-Plasse, N.; Jackson, P.; Grosgogeat, B.; Colon, P. Bioactive Glass for Dentin Remineralization: A Systematic Review. Mater. Sci. Eng. C 2017, 76, 1369-1377. [CrossRef] [PubMed]

24. Bartos, A.; Nagy, K.; Anggono, J.; Antoni Purwaningsih, H.; Móczó, J.; Pukánszky, B. Biobased PLA/Sugarcane Bagasse Fiber Composites: Effect of Fiber Characteristics and Interfacial Adhesion on Propertie. Compos. Part A Appl. Sci. Manuf. 2021, 143, 106273. [CrossRef]

25. Chuan, D.; Fan, R.; Wang, Y.; Ren, Y.; Wang, C.; Du, Y.; Zhou, L.; Yu, J.; Gu, Y.; Chen, H.; et al. Stereocomplex Poly(Lactic Acid)-Based Composite Nanofiber Membranes with Highly Dispersed Hydroxyapatite for Potential Bone Tissue Engineering. Compos. Sci. Technol. 2020, 192, 108107. [CrossRef]

26. Rocha, C.R.; Chávez-Flores, D.; Zuverza-Mena, N.; Duarte, A.; Rocha-Gutiérrez, B.A.; Zaragoza-Contreras, E.A.; Flores-Gallardo, S. Surface Organo-modification of Hydroxyapatites to Improve PLA/HA Compatibility. J. Appl Polym Sci 2020, 137, 49293. [CrossRef] 
27. Fang, Z.; Feng, Q. Improved Mechanical Properties of Hydroxyapatite Whisker-Reinforced Poly(L-Lactic Acid) Scaffold by Surface Modification of Hydroxyapatit Mater. Sci. Eng. C 2014, 35, 190-194. [CrossRef]

28. Wang, X.; Song, G.; Lou, T. Fabrication and Characterization of Nano-Composite Scaffold of PLLA/Silane Modified Hydroxyapatit. Med Eng. Phys. 2010, 32, 391-397. [CrossRef]

29. Tsuji, H.; Ikada, Y. Stereocomplex Formation between Enantiomeric Poly(Lactic Acids). 9. Stereocomplexation from the Melt. Macromolecules 1993, 26, 6918-6926. [CrossRef]

30. Nakajima, M.; Nakajima, H.; Fujiwara, T.; Kimura, Y.; Sasaki, S. Nano-Ordered Surface Morphologies by Stereocomplexation of the Enantiomeric Polylactide Chains: Specific Interactions of Surface-Immobilized Poly(D-Lactide) and Poly(Ethylene Glycol)Poly(L-Lactide) Block Copolymer. Langmuir 2014, 30, 14030-14038. [CrossRef]

31. Fan, X.; Wang, M.; Yuan, D.; He, C. Amphiphilic Conetworks and Gels Physically Cross-Linked via Stereocomplexation of Polylactid. Langmuir 2013, 29, 14307-14313. [CrossRef] [PubMed]

32. Tsuji, H.; Matsumura, N.; Arakawa, Y. Stereocomplex Crystallization and Homo-Crystallization of Star-Shaped Four-Armed Stereo Diblock Poly(Lactide)s during Precipitation and Non-Isothermal Crystallization. Polym J. 2016, 48, 1087-1093. [CrossRef]

33. Tsuji, H.; Ikada, Y.; Hyon, S.-H.; Kimura, Y.; Kitao, T. Stereocomplex Formation between Enantiomeric Poly(Lactic Acid). VIII. Complex Fibers Spun from Mixed Solution of Poly(D-Lactic Acid) and Poly(L-Lactic Acid). J. Appl. Polym. Sci. 1994, 51, 337-344. [CrossRef]

34. Tsuji, H.; Tezuka, Y. Stereocomplex Formation between Enantiomeric Poly(Lactic Acid) 12. Spherulite Growth of Low-MolecularWeight Poly(Lactic Acid)s from the Melt. Biomacromolecules 2004, 5, 1181-1186. [CrossRef] [PubMed]

35. Bai, D.; Liu, H.; Ju, Y.; Deng, S.; Bai, H.; Zhang, Q.; Fu, Q. Low-Temperature Sintering of Stereocomplex-Type Polylactide Nascent Powder: The Role of Poly(Methyl Methacrylate) in Tailoring the Interfacial Crystallization between Powder Particle. Polymer 2020, 210, 123031. [CrossRef]

36. Fernandes Nassar, S.; Delpouve, N.; Sollogoub, C.; Guinault, A.; Stoclet, G.; Régnier, G.; Domenek, S. Impact of Nanoconfinement on Polylactide Crystallization and Gas Barrier Propertie. ACS Appl. Mate Interfaces 2020, 12, 9953-9965. [CrossRef]

37. Jing, Y.; Quan, C.; Liu, B.; Jiang, Q.; Zhang, A. Mini Review on the Functional Biomaterials Based on Poly(Lactic Acid) Stereocomplex. Polym. Rev. 2016, 56, 262-286. [CrossRef]

38. Kum, H.; Cho, Y.; Seo, S.H.; Joung, Y.K.; Ahn, D.J.; Han, D.K. A Poly(Lactide) Stereocomplex Structure with Modified Magnesium Oxide and Its Effects in Enhancing the Mechanical Properties and Suppressing Inflammation. Small 2014, 10, 3783-3794. [CrossRef]

39. Jing, Z.; Shi, X.; Zhang, G.; Li, J. Rheology and Crystallization Behavior of PLLA/TiO 2 -g-PDLA Composites: Rheology and Crystallization Behavior of PLLA/TiO2-g-PDLA Composite. Polym. Adv. Technol. 2015, 26, 528-537. [CrossRef]

40. Li, Z.; Yuan, D.; Jin, G.; Tan, B.H.; He, C. Facile Layer-by-Layer Self-Assembly toward Enantiomeric Poly(Lactide) Stereocomplex Coated Magnetite Nanocarrier for Highly Tunable Drug Deliverie. ACS Appl. Mate Interfaces 2016, 8, 1842-1853. [CrossRef]

41. Li, Y.; Han, C.; Zhang, X.; Xu, K.; Bian, J.; Dong, L. Poly(L-Lactide)/Poly(D-Lactide)/Clay Nanocomposites: Enhanced Dispersion, Crystallization, Mechanical Properties, and Hydrolytic Degradation. Polym. Eng. Sci. 2014, 54, 914-924. [CrossRef]

42. Huang, G.; Du, Z.; Yuan, Z.; Gu, L.; Cai, Q.; Yang, X. Poly(L-Lactide) Nanocomposites Containing Poly(D-Lactide) Grafted Nanohydroxyapatite with Improved Interfacial Adhesion via Stereocomplexation. J. Mech. Behav. Biomed. Mater. 2018, 78, 10-19. [CrossRef]

43. Liu, C.; Lin, C.; Feng, X.; Wu, Z.; Lin, G.; Quan, C.; Chen, B.; Zhang, C. A Biomimicking Polymeric Cryogel Scaffold for Repair of Critical-Sized Cranial Defect in a Rat Model. Tissue Eng. Part A 2019, 25, 1591-1604. [CrossRef]

44. Nogueira, D.; Scheeren, L.E.; Pilar Vinardell, M.; Mitjans, M.; Rosa Infante, M.; Rolim, M.B. Nanoparticles Incorporating PHResponsive Surfactants as a Viable Approach to Improve the Intracellular Drug Delivery. Mater. Sci. Eng. C 2015, 57, 100-106. [CrossRef]

45. Chu, L.; Jiang, G.; Hu, X.-L.; James, T.D.; He, X.-P.; Li, Y.; Tang, T. Biodegradable Macroporous Scaffold with Nano-Crystal Surface Microstructure for Highly Effective Osteogenesis and Vascularization. J. Mate Chem. B 2018, 6, 1658-1667. [CrossRef]

46. Razavi, M.; Cheng, S.; Huang, D.; Zhang, S.; Wang, S.-Q. Crazing and Yielding in Glassy Polymers of High Molecular Weight. Polymer 2020, 197, 122445. [CrossRef]

47. Deblieck, A.; van Beek, D.J.M.; Remerie, K.; Ward, I.M. Failure Mechanisms in Polyolefines: The Role of Crazing, Shear Yielding and the Entanglement Network. Polymer 2011, 52, 2979-2990. [CrossRef]

48. Razavi, M.; Wang, S.-Q. Why Is Crystalline Poly(Lactic Acid) Brittle at Room Temperature? Macromolecules 2019, 52, 5429-5441. [CrossRef]

49. Xu, J.-Z.; Zhang, Z.-J.; Xu, H.; Chen, J.-B.; Ran, R.; Li, Z.-M. Highly Enhanced Crystallization Kinetics of Poly(L-Lactic Acid) by Poly(Ethylene Glycol) Grafted Graphene Oxide Simultaneously as Heterogeneous Nucleation Agent and Chain Mobility Promote. Macromolecules 2015, 48, 4891-4900. [CrossRef]

50. Wang, L.; Wang, Y.N.; Huang, Z.G.; Weng, Y.X. Heat resistance, crystallization behavior, and mechanical properties of polylactide/nucleating agent composite. Mater. Des. 2015, 66, 7-15. [CrossRef]

51. Baldenegro-Perez, L.A.; Navarro-Rodriguez, D.; Medellin-Rodriguez, F.J.; Hsiao, B.; Avila-Orta, A.; Sics, I. Molecular Weight and Crystallization Temperature Effects on Poly(ethylene terephthalate) (PET) Homopolymers, an Isothermal Crystallization Analysi. Polymers 2014, 6, 583-600. [CrossRef] 